
$\frac{216}{2-25 \cdot 77}$

\title{
EQUATION OF STATE OF WATER
}

Francis H. Ree

December 20, 1976

\section{MASTER}

Prepared for U.S. Energy Research \& Development Administration under contract No. W-7405-Eng-48

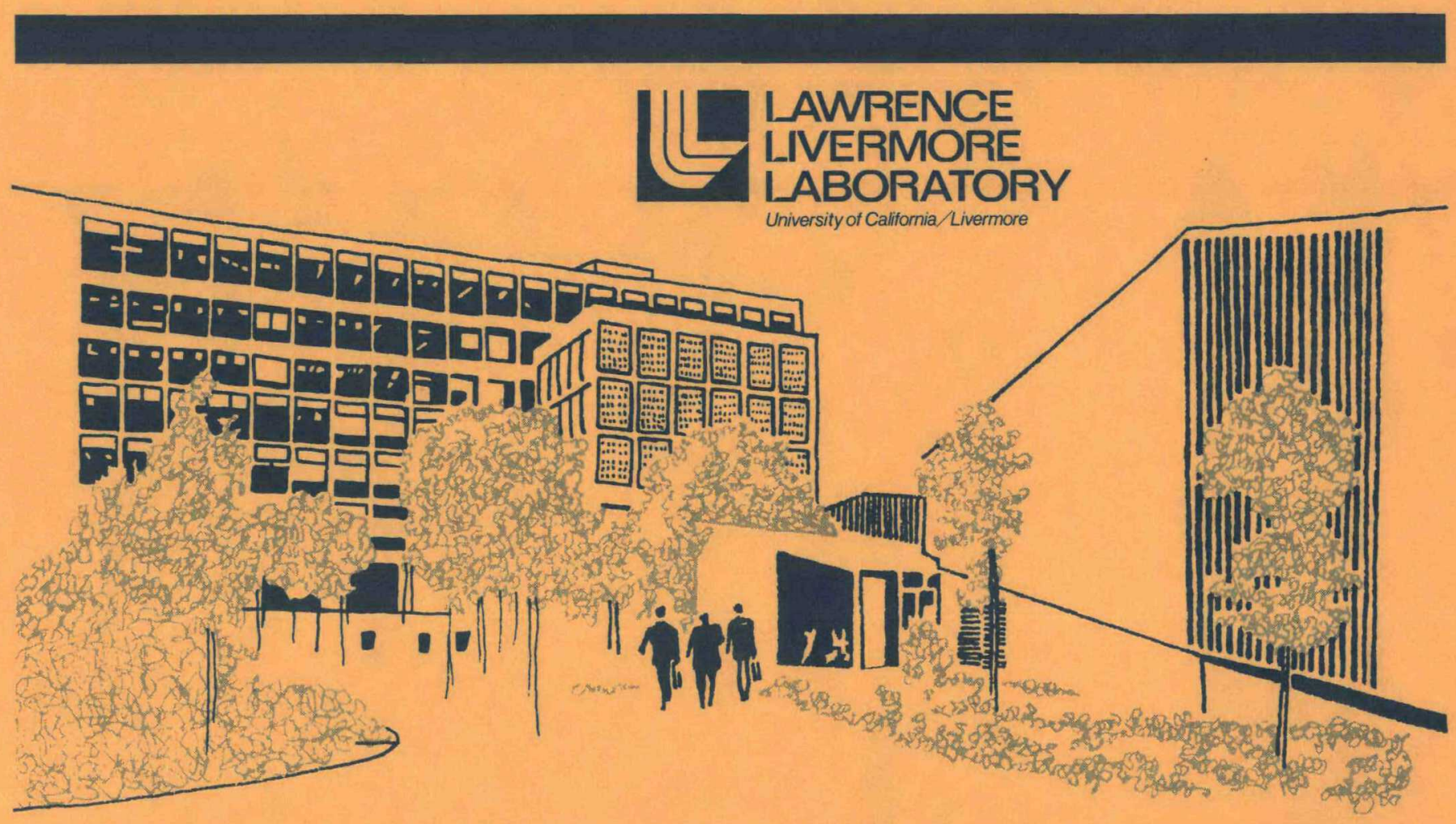




\section{NOTICE}

This report was prepared as an account of work sponsored by the United States Government. Neither the United States nor the United States Energy Research \& Development Administration, nor any of their employees, nor any of their contractors, subcontractors, or their employees, makes any warranty, express or implied, or assumes any legal liability or responsibility for the accuracy, completeness or usefulness of any information, apparatus, product or process disclosed, or represents that its use would not infringe privately-owned rights.

\section{NOTICE}

Reference to a company or product name does not imply approval or recommendation of the product by the University of California or the U.S. Energy Research \& Development Administration to the exclusion of others that may be suitable.

Printed in the United States of America

$$
\text { Available from }
$$

National Technical Information Service

U.S. Department of Commerce

5285 Port Royal Road

Springfield, VA 22161

Price: Printed Copy $\$$; Microfiche $\$ 3.00$

\begin{tabular}{|c|c|c|c|}
\hline Page Range & $\begin{array}{c}\text { Domestic } \\
\text { Price } \\
\end{array}$ & Page Range & $\begin{array}{c}\text { Domestic } \\
\text { Price } \\
\end{array}$ \\
\hline $001-025$ & $\$ 3.50$ & $326-350$ & 10.00 \\
\hline $026-050$ & 4.00 & $351-375$ & 10.50 \\
\hline $051-075$ & 4.50 & $376-400$ & 10.75 \\
\hline $076-100$ & 5.00 & $401-425$ & 11.00 \\
\hline $101-125$ & 5.50 & $426-450$ & 11.75 \\
\hline $126-150$ & 6.00 & $451-475$ & 12.00 \\
\hline $151-175$ & 6.75 & $476-500$ & 12.50 \\
\hline $176-200$ & 7.50 & $501-525$ & 12.75 \\
\hline $201-225$ & 7.75 & $526-550$ & 13.00 \\
\hline $226-250$ & 8.00 & $551-575$ & 13.50 \\
\hline $251-275$ & 9.00 & $576-600$ & 13.75 \\
\hline $276-300$ & 9.25 & $601-$ up & $*$ \\
\hline $301-325$ & 9.75 & & \\
\hline
\end{tabular}

*Add $\$ 2.50$ for each additional 100 page increment from 601 to 1,000 pages; add $\$ 4.50$ for each additional 100 page increment over 1,000 pages. 


\section{DISCLAIMER}

This report was prepared as an account of work sponsored by an agency of the United States Government. Neither the United States Government nor any agency Thereof, nor any of their employees, makes any warranty, express or implied, or assumes any legal liability or responsibility for the accuracy, completeness, or usefulness of any information, apparatus, product, or process disclosed, or represents that its use would not infringe privately owned rights. Reference herein to any specific commercial product, process, or service by trade name, trademark, manufacturer, or otherwise does not necessarily constitute or imply its endorsement, recommendation, or favoring by the United States Government or any agency thereof. The views and opinions of authors expressed herein do not necessarily state or reflect those of the United States Government or any agency thereof. 


\section{DISCLAIMER}

Portions of this document may be illegible in electronic image products. Images are produced from the best available original document. 


\section{近 \\ LAWRENCE LIVERMORE LABORATORY}

University of Callfornia /Livermore,California/94550

UCRL-52190

\section{EQUATION OF STATE OF WATER}

Francis H. Ree

MS. date: December 20, 1976

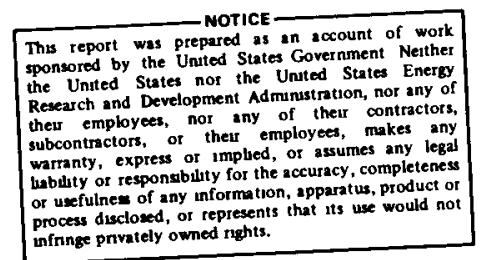





\section{Contents}

Abstract . . . . . . . . . . . . . . . . . . . . . . . . 1 Introduction . . . . . . . . . . . . . . . . . . . . . . . . 1

Construction of the EOS Data Basis . . . . . . . . . . . . . . . . . . 2 TIGER Region . . . . . . . . . . . . . . . . . . . . 4 OCCIPITAL Region . . . . . . . . . . . . . . . . . . 6 MASTER and TFCMIX Regions . . . . . . . . . . . . . . . 6

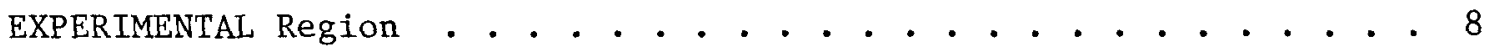

Data Reduction . . . . . . . . . . . . . . . . . . . 9 Discussions . . . . . . . . . . . . . . . . . . . 11 Shapes of the EOS Data . . . . . . . . . . . . . . . 11 Analytical Representations of the EOS Data . . . . . . . . . . . 11 Principal Hugoniot . . . . . . . . . . . . . . . 17 Hugoniot of Steam: High-Pressure Portion . . . . . . . . . . . 19 Hugoniot of Steam: Low-Pressure Portion . . . . . . . . . . . 21 Behavior of the TIGER Data . . . . . . . . . . . . . 27 Mixture of $\mathrm{SiO}_{2}$ and $\mathrm{H}_{2} \mathrm{O}$. . . . . . . . . . . . . . . . 30 Conclusion . . . . . . . . . . . . . . . . . . . . . . . 32 Acknowledgments . . . . . . . . . . . . . . . . . . . 32 References . . . . . . . . . . . . . . . . . . . . 33 


\title{
EQUATION OF STATE OF WATER
}

\begin{abstract}
An equation of state of water is constructed in the density range between $2 \mathrm{~g} / \mathrm{m}^{3}$ and $4 \times 10^{2} \mathrm{Mg} / \mathrm{m}^{3}$ and in the temperature range between $0.025 \mathrm{eV}$ (room temperature) and $25 \mathrm{keV}$ by combining several theoretical codes and experimental data. The liquid-vapor

phase change, Ionization process, and chemical equilibrium among dissociation products of water are a11 considered. Theoretical results and experimental data are compared and several interesting aspects of the thermodynamics of water are discussed.
\end{abstract}

\section{Introduction}

Approximately $2.2 \times 10^{21} \mathrm{~kg}$ of water exist in the oceans and within terrestrial rocks. About $36 \%$ of this water is contained in rocks as mineral hydrates. Water constitutes the most abundant compound on the surface of the earth. Without water, most living organisms cannot survive. In addition in our modern-day wor1d, an understanding of the physical properties of water is essential to many engineering and industrial applications.

The water contained in rocks has a much lower boiling temperature than that of the rocks themselves and thus the pressure generated from vaporized water can drastica1ly alter the cavity formation from an underground explosion (conventional or nuclear). The high energy released by the explosion can produce a shock wave of several hundred terapascals which heats the rock-contained water to several kiloelectron volts. This shock compression is usually accompanied by an adiabatic expansion that brings the system to the lowdensity, gaseous-phase region and, upon further cooling, takes it into the liquid-vapor transition region. The properties of water must be known over a wide range of variables if cavity formation is to be accurately predicted.

An understanding of the properties of water is also essential to another current problem area; namely, safeguarding against a "loss-of-coolant" accident associated with a nuclear reactor. In such a situation, steam and air under pressure, generated as 
a result of the loss of coolant, is vented into a pool of cold liquid water, thus relieving the dangerously high pressures. Here, the thermodynamic properties of water are required only over a limited range but, obviously, with great accuracy. The physically important range mainly spans the liquid-vapor transition region but still, the highest densities forseeable reach severalpercent compression.

A material-response code designed to study these water-related problems may require thermodynamic data of water in the range from $2 \mathrm{~g} / \mathrm{m}^{3}$ to
$4 \times 10^{2} \mathrm{Mg} / \mathrm{m}^{3}$ in density $(\rho)$ and from $0.025 \mathrm{eV}$ (room temperature) to $25 \mathrm{keV}$ in temperature ( $\mathrm{T})$. Within this range the thermodynamic behavior of water is complex. In addition to normal thermodynamic phase changes, we must consider dissociation and ionization of water molecules. Although water has been studied extensively, ${ }^{1-6}$ available experimental data do not cover the entire $\rho-T$ region required. In this report, we provide a consistent, global equation of state (EOS) for water which encompasses all states of water that may be reached in experimental and working situations.

\section{Construction of the EOS Data Basis}

As described earlier, the EOS data are desired for densities from $2 \mathrm{~g} / \mathrm{m}^{3}$ to $4 \times 10^{2} \mathrm{Mg} / \mathrm{m}^{3}$ and for temperatures from $0.025 \mathrm{eV}$ to 25 $\mathrm{keV}$ a nearly complete range for any practical application. Understandably, a single theoretical model cannot cover this entire range. Therefore, we have combined several theoretical models, each appropriate over different temperature and density ranges, with available experimental data to develop an EOS that is consistent over this wide range. This procedure has proved to be useful in obtaining the EOS data of various plastics ${ }^{7}$ and of $\mathrm{SiO}_{2} \cdot 8$ Details of the theoretical models and their required approximations have been described in Refs. 7 and 8, as well as in the references quoted therin. Only a brief description of the models relevant to water is necessary for our present purpose.

Figure 1 indicates the five different $\rho-T$ subregions: four theoretical regions plus one experimental region. These are the TIGER, OCCIPITAL, TFCMIX, and MASTER regions, where each name refers to an appropriate theoretical code used in the regions, and the EXPERIMENTAL region, 


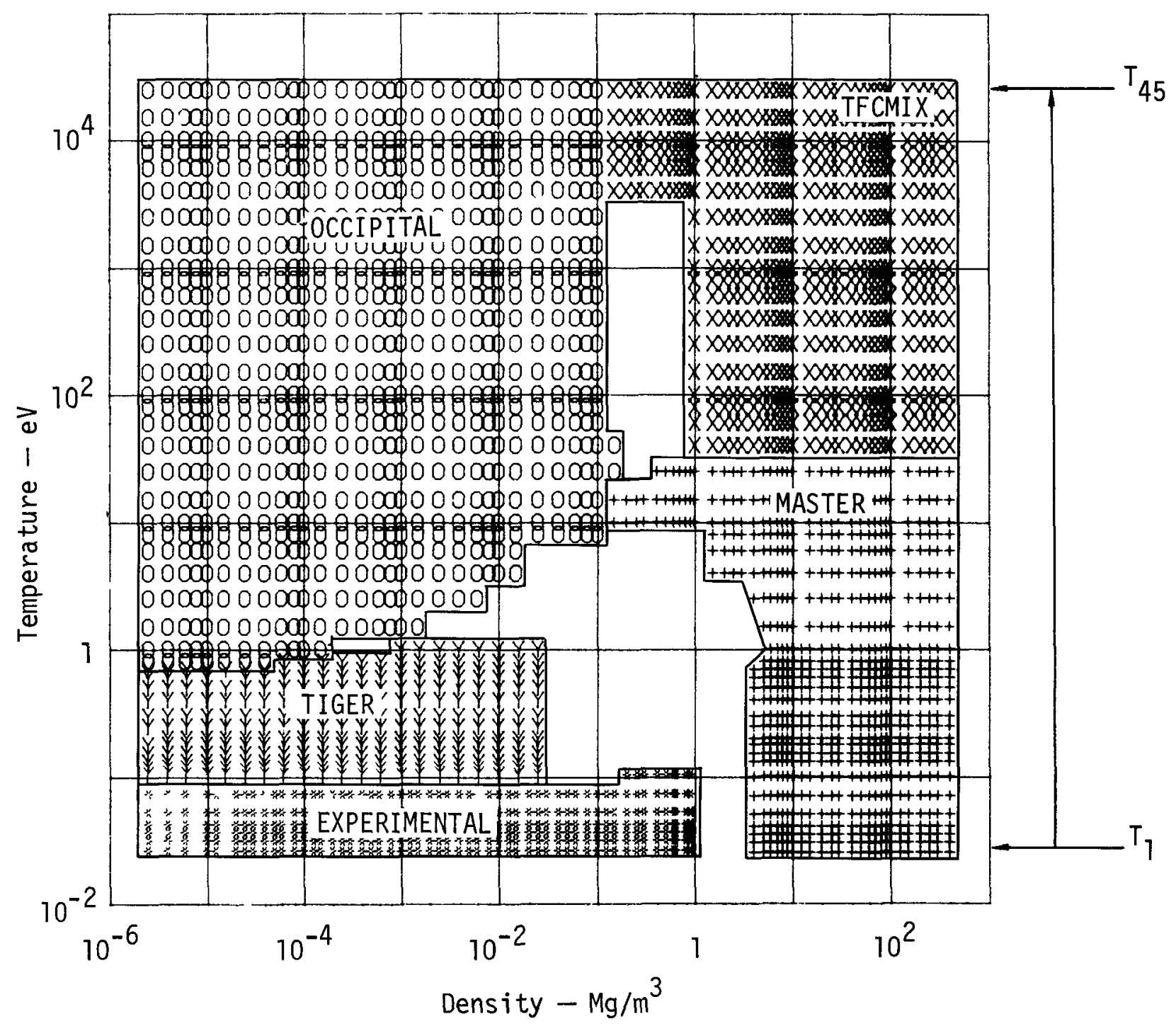

Fig. 1. The density and temperature regions of the four theoretical codes (TIGER, OCCIPITAL, TFCMIX, and MASTER) plus the experimental data used to obtain the EOS data of water. The data are taken at points shown. There are 45 isotherms as denoted by $\mathrm{T}_{i}(i=1,2, \ldots 45)$. These are: 0.025 , $0.03,0.035,0.04,0.05,0.07,0.1,0.13,0.15,0.18,0.2,0.25,0.3,0.4$, $0.5,0.6,0.7,0.8,1.0,1.5,2.5,4,6,8,10,15,25,40,60,80,100$, $150,250,400,600,800,1000,1500,2500,4000,6000,8000,10000,15000$, and $25000 \mathrm{eV}$. 
where the experimental data are employed. In this report we have simply extended the liquid phase to the high-density region where ice is actually a stable phase and therefore, the thermodynamics of ice are treated only approximately。

\section{TIGER REGION}

Within this region, the ionization is negligible but, because of the moderately high-temperature and lowdensity environment encountered here, the EOS data are sensitive to the chemical equilibria of the dissociated species of $\mathrm{H}_{2} \mathrm{O}$ as well as of $\mathrm{H}_{2} \mathrm{O}$ itself.

The TIGER code calculates the EOS data for a heterogeneous system of a mixture containing gaseous and condensed components. ${ }^{9}$ The gaseous species chosen in the present calculation are $\mathrm{O}, \mathrm{O}_{2}, \mathrm{H}, \mathrm{H}_{2}, \mathrm{OH}$, and $\mathrm{H}_{2} \mathrm{O}$. In addition, the calculation also includes the liquid $\mathrm{H}_{2} \mathrm{O}$. The pressure for the gaseous mixture is calculated from the BKW (BeckerKistiakowsky-Wilson) equation. ${ }^{10}$ The "covolume" parameters in the BKW equation as well as the enthalphy changes, entropies at room temperature and at standard state, and analytical fits to the specific heat data have been provided by $\mathrm{J}$. Walton and E. Lee ${ }^{11}$ for our present work. These data are summarized in Table 1。 The 1iquid-state EOS expression of water for TIGER was chosen to be

$$
\begin{aligned}
& \text { V(1iquid } \left.\mathrm{H}_{2} \mathrm{O}\right)=16.94+0.03803 \mathrm{~T}-2.602 .10^{-6} \mathrm{~T}^{2} \\
& +\left(-1.48 .10^{-4}+3.439 .10^{-8} \mathrm{~T}+2.198 .10^{-11} \mathrm{~T}^{2}\right) \mathrm{P} \\
& \quad+\left(5.434 .10^{-10}-3.037 .10^{-13} \mathrm{~T}-1.342 .10^{-17} \mathrm{~T}^{2}\right) \mathrm{P}^{2}
\end{aligned}
$$

where the molar volume $\mathrm{V}$ is expressed in units of $10^{-6} \mathrm{~m}^{3} / \mathrm{mol}$, the temperature $\mathrm{T}$ in Kelvins, and the pressure in atmospheres $(0.101325 \mathrm{MPa})$. The above expression correctly reproduces the observed bulk modulus at standard state and room temperature. It was obtained by refitting a semitheoretical EOS expression of Gurtman et al. , 6 which is based on the hydrostatic data of Bridgman as reported in Ref. 6 and on Rice and Walsh's data deduced from the shock-wave experiments. ${ }^{4}$ Equation (1) is applicable for $T \lesssim 1600 \mathrm{~K}$, $P \lesssim 25 \mathrm{GPa}$, and $\rho \lesssim 2.2 \mathrm{Mg} / \mathrm{m}^{3}$. The average error between Eq. (1) and Gurtman et al.' 's expression ${ }^{6}$ over this range is about $7.5 \%$. However, because a polynomial of Eq. (1) has a rather constrained form which cannot fit the EOS data 
Table 1. The parameters in the TIGER code for the equilibrium mixtures of $\mathrm{H}_{2} \mathrm{O}^{\mathrm{a}}$

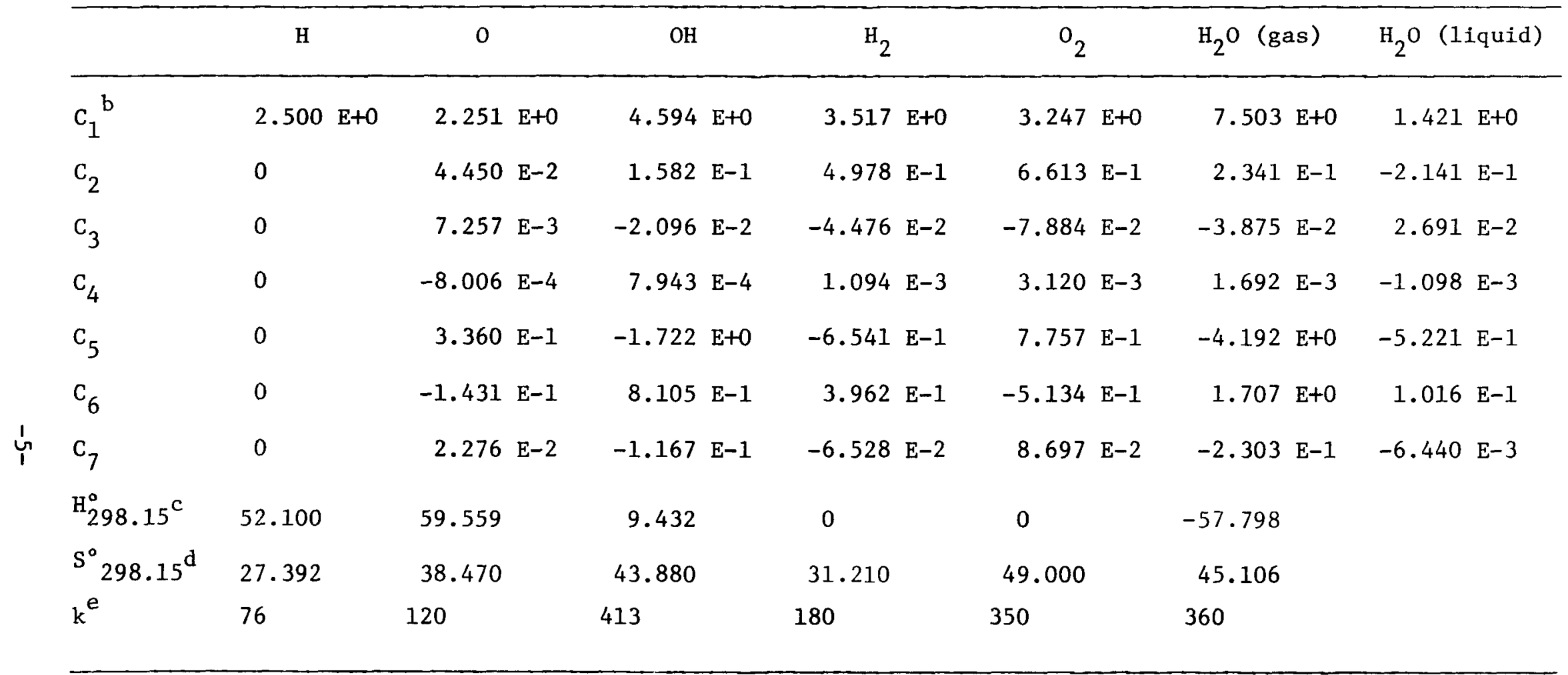

a Data provided by J. Walton and E. Lee (see Ref. 11).

${ }^{\mathrm{b}} \mathrm{C}_{\mathrm{p}}(\mathrm{T}) / \mathrm{R} \equiv \mathrm{C}_{1}+\mathrm{C}_{2} \theta+\mathrm{C}_{3} \theta^{2}+\mathrm{C}_{4} \theta^{3}+\mathrm{C}_{5} \theta^{-1}+\mathrm{C}_{6} \theta^{-2}+\mathrm{C}_{7} \theta^{-3} ; \theta \equiv \mathrm{T} / 1000$.

c Heat of formation in $\mathrm{kcal} / \mathrm{mol}$ at standard state and $298.15 \mathrm{~K}$ (see Ref. 12).

d Entropy in cal/mol/K at standard state and 298.15 (see Ref. 12).

e Covolume in the BKW equation (Ref. 10) in $\mathrm{K}^{0.5} \cdot \mathrm{cm}^{3} / \mathrm{mol}$. 
over a large range of pressure, the deviation between the two approaches can become as large as $17 \%$.

The TIGER region included in our data basis has an approximately rectangular shape in $\rho$ and $\mathrm{T}$ coordinates with $\rho$ between $2 \mathrm{~g} / \mathrm{m}^{3}$ and $2.5 \mathrm{Mg} / \mathrm{m}^{3}$ and $\mathrm{T}$ between 0.1 and $1.0 \mathrm{eV}$. We chose the upper temperature boundary so that ionization contributions would be negligible. The lower temperature boundary was set so that the available experimental data could be used below it. Comparison of the EOS data between the TIGER calculation and the experimental data below $0.1 \mathrm{eV}$ will be presented in a later section of this work. Note that the upper left-hand corner (low- $\rho$ and high-T portion) of the TIGER region in Fig. 1 was trimmed and replaced by the OCCIPITAL generated data because the ionization becomes significant in this area. When the density exceeds the upper end $\left(2.5 \mathrm{Mg} / \mathrm{m}^{3}\right)$ of the TIGER region, the nonideal (repulsive) contribution to the pressure in the BKW equation produces an undesirably large pressure. Thus, the TIGER data beyond $2.5 \mathrm{Mg} / \mathrm{m}^{3}$ were not used. The energy of formation of liquid $\mathrm{H}_{2} \mathrm{O}$ at standard state and room temperature is $15.6 \mathrm{~kJ} / \mathrm{g}\left(15.6 \mathrm{GPa} \cdot \mathrm{m}^{3} / \mathrm{Mg}\right) .^{12}$ The internal energy (E) values in the present work are referred from this standard state.

\section{OCCIPITAL REGION}

Here, $\mathrm{H}_{2} \mathrm{O}$ is assumed to be completely dissociated into ions, electrons, and neutral atomic hydrogen and oxygen. The concentrations of these species are obtained from the Saha equation. ${ }^{13}$ Thermodynamic properties are calculated by assuming that the dissociated species behave like an ideal gas. The OCCIPITAL code used here is provided by Cortez and Lacey. 14 We used it to generate the EOS data in the region of $\rho$ approximately less than $0.1 \mathrm{Mg} / \mathrm{m}^{3}$ and $\mathrm{T}$ greater than $0.8 \mathrm{eV}$. The lower right corner (corresponding to the high- $\rho$, low-T portion) of the OCCIPITAL region was not included in the final data basis because contribution from the partially ionized molecular species may be important in this region. A constant, $53.57 \mathrm{MJ} / \mathrm{g}$, is added to the OCCIPITAL-generated $\mathrm{E}$ (which is relative to the separated un-ionized states at $T=0 \mathrm{~K}$ ) to refer it to the standard state used in the present work.

\section{MASTER AND TFCMIX REGIONS}

The theromdynamic properties in these regions are evaluated by the Thomas-Fermi Theory with several corrections. 15 These are Kirzhnits' correction $^{16}$ to account for the wave nature of electrons and the electron exchange contribution plus Warren's 
correction $^{17}$ for the thermal contribution of nuclei. In addition, a mixture model is used in which the volume and energy of $\mathrm{H}_{2} \mathrm{O}$ are assumed to be the sums of the volumes and energies of individual atomic species of oxygen and hydrogen in a 1-to-2

ratio at constant temperature and electron pressure. The internal energies were shifted in the same manner as the OCCIPITAL energies to refer to the standard state.

The TFCMIX region corresponds approximately to $\rho \gtrsim 0.1$ to $1.0 \mathrm{Mg} / \mathrm{m}^{3}$ and $\mathrm{T} \geq 40 \mathrm{eV}$. Below $40 \mathrm{eV}$, electronic correlations and atomic shell structures become important. To correct these deficiencies phenomenologically, the MASTER code ${ }^{18}$ generates a new $\mathrm{O}-\mathrm{K}$ isotherm. The lower-pressure portion of the new $\mathrm{O}-\mathrm{K}$ isotherm was obtained from the Grüneisen model,

$$
P_{H}-P_{O}=(\gamma / V)\left(E_{H}-E_{O}\right),
$$

by solving for the $0-K$ quantities, $E_{o}$, and $P_{o}=-\partial E_{o} / \partial V$. The experimentally determined Hugoniot quantities $\left(\mathrm{P}_{\mathrm{H}}\right.$ and $\left.\mathrm{E}_{\mathrm{H}}\right)$ and the Grüneisen $\gamma$ expressed as a polynomial in $V$, where also used such that

$$
\begin{aligned}
\gamma=- & 239.703+3081.87 \mathrm{v}-16345.9 \mathrm{v}^{2}+46506.6 \mathrm{v}^{3}-76706.8 \mathrm{v}^{4} \\
+ & 73499.3 \mathrm{v}^{5}-37987.4 \mathrm{v}^{6}+8192.56 \mathrm{v}^{7}
\end{aligned}
$$

where $\mathrm{V}$ is in units of $\mathrm{m}^{3} / \mathrm{Mg}$.

Equation (3) agrees within $10 \%$, over $\mathrm{V}$ between 0.45 and $1.0018 \mathrm{~m}^{3} / \mathrm{Mg}$, to the expression of Gurtman et a1. 6 who estimated $\gamma$ from the static and Hugoniot data. Such agreement can be considered satisfactory because the uncertainty in the experimental data is at least as great. The Hugoniot quantities $\mathrm{P}_{\mathrm{H}}$ and $\mathrm{E}_{\mathrm{H}}$ in $\mathrm{Eq}$ 。(2) are obtained from the Rankine-Hugoniot relation using the shock velocity $\left(U_{s}\right)$ vs particle velocity $\left(U_{p}\right)$ relation (in $\mathrm{km} / \mathrm{s}$ ):

$$
U_{S}=1.4829+2.1057 U_{p}-0.1744 U_{p}^{2}+0.010085 U_{p}^{3} .
$$

This accurately represents the experimental data of Walsh and Rice 19 and of Skidmore and Morris to $U_{p} \simeq$ $8.7 \mathrm{~km} / \mathrm{s}$ or $U_{\mathrm{s}} \simeq 13 \mathrm{~km} / \mathrm{s}$ as compiled by Van Thiel et al. 20 MASTER uses the constant volume specific heat $\left(C_{v}\right)$ of $3 R / \bar{A}(\bar{A}=$ average atomic weight $=18.015 / 3$ ) to shift $E_{0}$ to the 
energy reference used in the present work.

The 0-K isotherm from the MieGrüneisen model is used only for $\mathrm{P} \leq 15 \mathrm{GPa}$, corresponding to the Hugoniot pressure of $39 \mathrm{GPa}$ or to 54 vol \% compression. This is unfortunate because Hugoniot data are available to $0.1 \mathrm{TPa}$. However, this choice was necessary because the Grüneisen $\gamma$ expression [Eq. (3)] becomes unreliable for $\mathrm{V} \leq 0.45 \mathrm{~m}^{3} / \mathrm{Mg}$.

The higher-pressure portion of the new $\mathrm{O}-\mathrm{K}$ isotherm $(\mathrm{P} \geq 20 \mathrm{TPa})$ was assumed to be the same as the $0-K$ isotherm of the TFCMIX code. In the intermediate range of $\mathrm{P}$ (i.e., between $15 \mathrm{GPa}$ and $20 \mathrm{TPa}$ ), a smooth interpolation was made to join the lower and the upper portions of the $0-\mathrm{K}$ isotherm. The other finite-T isotherms were obtained by rescaling the TFCMIX isotherms, adding at each density a quantity that is equal to the difference between the new $0-K$ isotherm and the TFCMIX $0-\mathrm{K}$ isotherm.

\section{EXPERIMENTAL REGION}

This region is approximately rectangular in shape and is bounded by $\mathrm{T} \leq 0.08$ to $0.1 \mathrm{eV}$ and $\rho \leq 1.0$ to $1.25 \mathrm{Mg} / \mathrm{m}^{3}$. Three different experimental sources are used here; Schmidt's steam table ${ }^{3}$, Burnham et al's static compression data ${ }^{3}$, and Bridgman's work as reported in Refs. 4 and 6 .
The pressures at $\rho=1.25 \mathrm{Mg} / \mathrm{m}^{3}$ and $\mathrm{T}=0.025,0.03$, and $0.04 \mathrm{eV}$ are obtained by graphically extrapolating or interpolating Bridgman's data. The corresponding energies are calculated by assuming that $\mathrm{C}_{\mathrm{V}}$ is equal to $3.27 \mathrm{~J} / \mathrm{g} \cdot \mathrm{K}$. The assumption of a constant $\mathrm{C}_{\mathrm{v}}$ in the $\mathrm{p}-\mathrm{T}$ range described above has been discussed by Gurtman et a1. ${ }^{6}$ who concluded that the above value for $\mathrm{C}_{\mathrm{v}}$ is reasonable. The thermodynamic data up to $0.1 \mathrm{GPa}$ were taken directly from the steam table while those above $0.1 \mathrm{GPa}$ were obtained by Burnham et al. ${ }^{21}$ from the following two empirical polynomials:

$$
\begin{aligned}
& P V=\sum_{j=0}^{9} \sum_{i=0}^{9-j} a_{i j} T^{i} P^{j}, \\
& P V=\sum_{j=0}^{8} \sum_{i=0}^{8-j} a_{i j} T^{i} P^{-j},
\end{aligned}
$$

depending on different ranges of $T$ and $P$. Numerical values of 55 $a_{i j}$ coefficients in Eq. (5) and 45 in $\mathrm{Eq}$. (6) that can reproduce the experimental specific volume data to $1 \mathrm{GPa}$ and $1173 \mathrm{~K}$ within $0.3 \%$ are given by Burnham et a1. 3 They have also used a polynomial similar to Eq. (5) to extrapolate the data to $1373 \mathrm{~K}$ and to $1 \mathrm{GPa}$; this data was also included in our present work. 
DATA REDUCTION

To generate the EOS data over an entire $\rho-T$ plane in Fig. 1, the EOS data from each of the theoretical codes described above are generated over a sufficiently large region. Next, each region must be trimmed until the energy and pressure isotherms and isochores from the neighboring regions appear to be a smooth continuation of each other. Figure 2 illustrates the final "trimmed-down" isotherms of pressure and energy, respectively, for the $\rho-T$ data points in Figure 1.

The "hole" regions in Fig. 1 where the theories become unreliable must be filled by a suitable interpolation. There are essentially three different hole regions in Fig. 1. The degree of difficulty of filling the holes is directly related to the extent of deviation from the ideal-gas behavior. As can be seen in Fig. 2, the easiest region to interpolate is the one bounded by the OCCIPITAL and the TFCMIX regions as well as between the OCCIPITAL and the MASTER regions for $\mathrm{T} \geq 2.5 \mathrm{eV}$.

The hole region most difficult to interpolate occurs in density between $1.25 \mathrm{Mg} / \mathrm{m}^{3}$ and $4 \mathrm{Mg} / \mathrm{m}^{3}$. This region joins the EXPERIMENTAL and the MASTER regions and is difficult to interpolate because the energy and the pressure are strongly increasing functions of density. The interpolations within this region are done iteratively until satisfactory data can be obtained.

The third hole region lies in temperature between 0.15 and $1.5 \mathrm{eV}$. It connects the TIGER and the MASTER as well as the low-T $(\leq 1.5 \mathrm{eV})$ OCCIPITAL data and the MASTER data. This region has a relatively large hole and is difficult to interpolate along each isotherm. The interpolations within this region are done bivariantly (in both $\rho$ and $\mathrm{T}$ ) after interpolating the first two hole regions that sandwich this third region.

The final EOS data are composed in a tabular form at $80 \rho$-points and 45 T-points, comprising the total 3600 data points. The $\rho$-grids used are multiples of $1,1.25,1.5,2$, $2.5,3,4,5,6$, and 8 between $2 \mathrm{~g} / \mathrm{m}^{3}$ and $400 \mathrm{Mg} / \mathrm{m}^{3}$ (except for $p=3 \times 10^{-6}, 5 \times 10^{-6}, 8 \times 10^{-6}$, $1.5 \times 10^{-5}, 50,80,100,125,200$, 250 , and $300 \mathrm{Mg} / \mathrm{m}^{3}$ ). The T-grids are multiples of $1,1.5,2.5,4,6$ and 8 between $2.5 \times 10^{-2}$ and $2.5 \times 10^{4} \mathrm{eV}$ (except for $\mathrm{T}=0.06$, and $0.08 \mathrm{eV})$. In addition, the isochores at $\rho=0.6309,0.9,1.02$, $1.04,1.08,1.14$, and $1.18 \mathrm{Mg} / \mathrm{m}^{3}$ as well as the isotherms at $\mathrm{T}=0.03$, $0.035,0.05,0.07,0.13,0.18,0.2$, $0.3,0.5$, and $0.7 \mathrm{eV}$ are included to 
Fig. 2. The pressure (a) and energy (b) isotherms of water over the data basis shown in Fig. 1 .
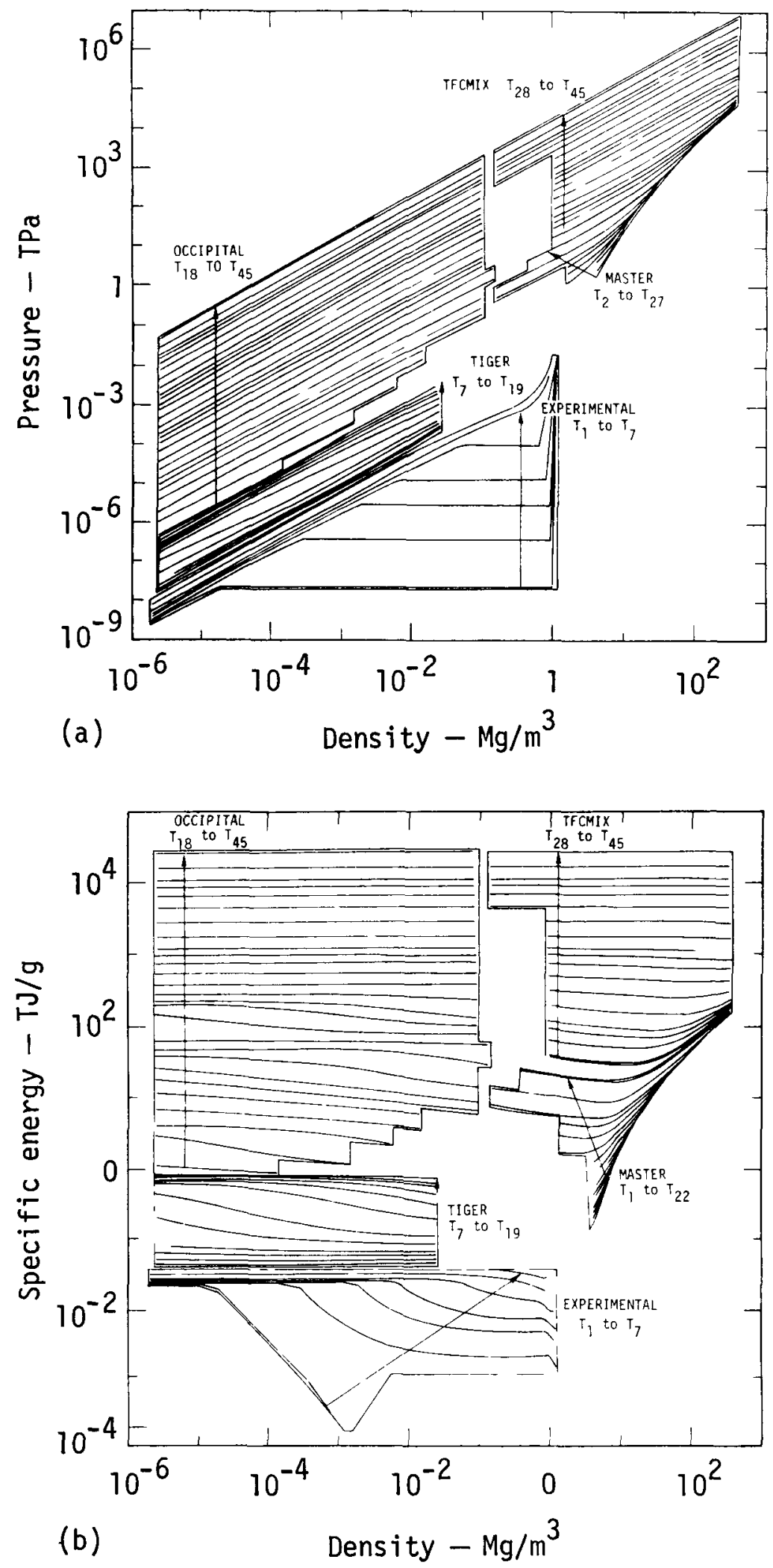
obtain the more detailed structure of the EOS data. The final pressure energy isotherms are shown in Fig. 3. Tables 2 and 3 list the values of $\mathrm{P}$ and $\mathrm{E}$, respectively, at selected $\mathrm{T}$ and $\rho$. This data is abstracted from the EOS table which is too large to be included in this report. $^{22}$ The present EOS table is constructed to be used with the LLL hydrocodes such as MEG, GRENDEL, and CORONET.

\section{Discussions}

SHAPES OF THE EOS DATA

The critical point of water occurs at $\mathrm{T}_{\mathrm{c}}=647.3 \mathrm{~K}, \mathrm{P}=21.408 \mathrm{MPa}$, and $\rho=0.305 \mathrm{Mg} / \mathrm{m}^{3}$. Within the 1iquidvapor two-phase region, the internal energy along an isotherm initially decreases steeply with density and then levels off until the liquid end of the transition region is reached. In the pure liquid region, the energy decreases again to $\rho=1.2 \mathrm{Mg} / \mathrm{m}^{3}$, above which the energy increases because of the repulsive interaction among the $\mathrm{H}_{2} \mathrm{O}$ molecules ( $\mathrm{Fig}$. $3 \mathrm{~b}$ ). At temperatures between 0.1 and 150 $\mathrm{eV}$, (the upper $\mathrm{T}$ corresponds to a nearly complete ionization of an oxygen atom, possibly excepting the last two, most tightly bound electrons), the influence of the ionization processes on the EOS behavior is significant as is evidenced by the ramped stairstep character in the energy isotherms in Fig. 3b.

Figure 4 shows the $P$ vs $E$ plots along isotherms ranging from room temperature to $773.15 \mathrm{~K}$ in the interval of $20 \mathrm{~K}$. The data shown here correspond to those within the EXPERIMENTAL region. The stairstep character in the $P$ vs $E$ isotherms corresponds to the liquid-vapor phase changes. At the transition, the energy drops from the higher (gaseous) values to the lower (liquid) values while the pressure obviously must remain constant. Figure 5 illustrates the corresponding $P$ vs $\rho$ isotherms.

ANALYTICAL REPRESENTATIONS OF THE EOS DATA

Many available material-response codes accept the EOS information only in an analytical form. For such codes, the EOS table developed in this study must be fitted into an appropriate analytical form. To fit the entire EOS table by a single expression with a limited number of parameters is a very difficult task. Therefore, a single analytical form is used here 
Fig. 3. The EOS data of water from the EOS table obtained in this study: (a) pressure isotherms, (b) energy isotherms.

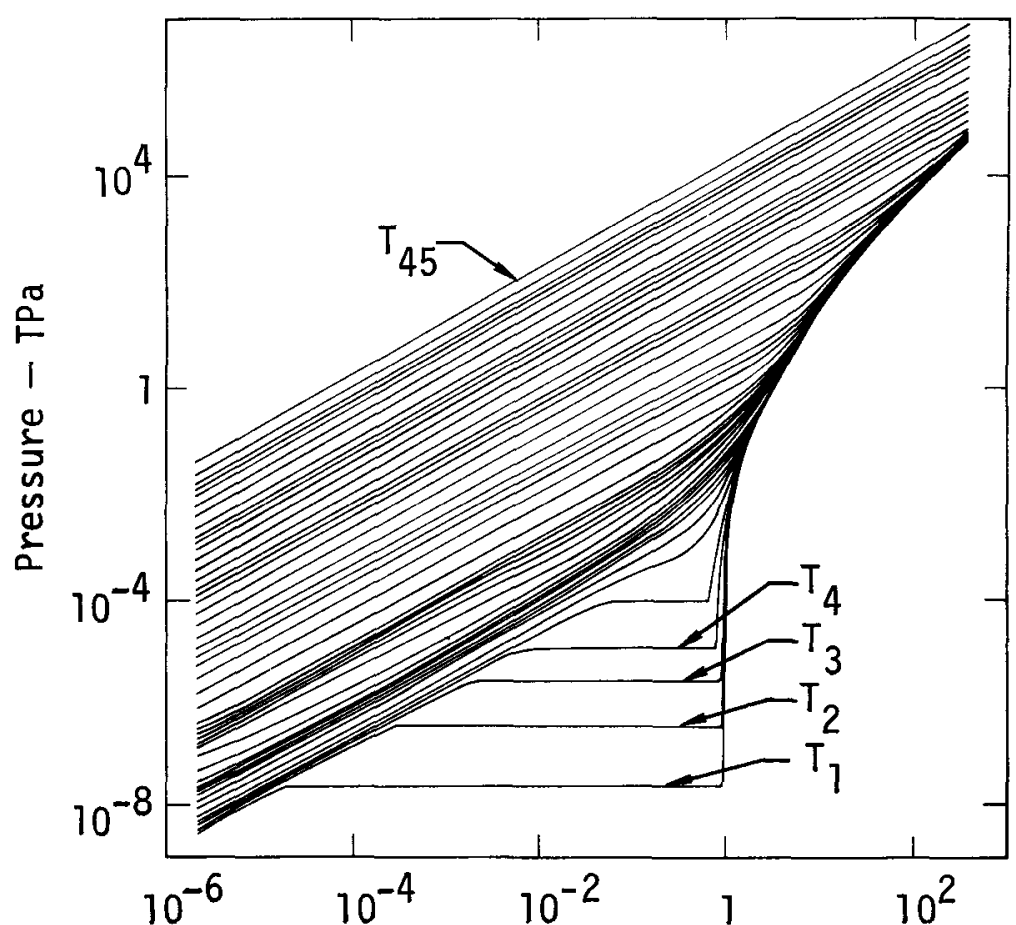

(a) Density $-\mathrm{Mg} / \mathrm{m}^{3}$

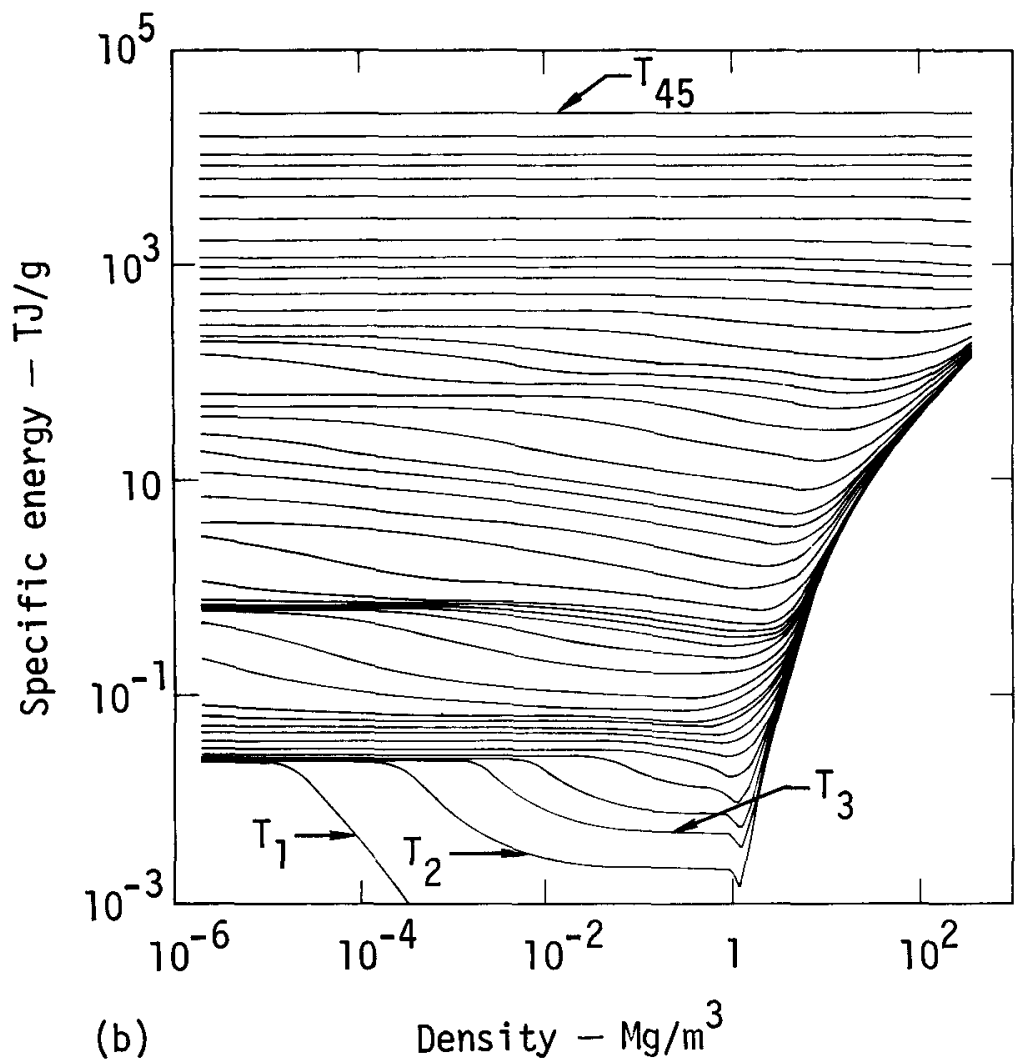


Table 2. Values of $\mathrm{P}$ at selected values of $\mathrm{T}$ and $\rho$ (abstracted from the complete EOS tab1e22).

DENSITY : TEMPERATURE (EV) PRESSURE (TPA)

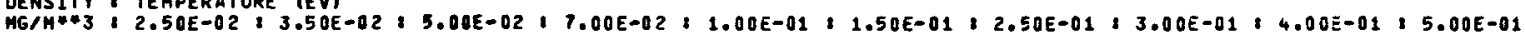

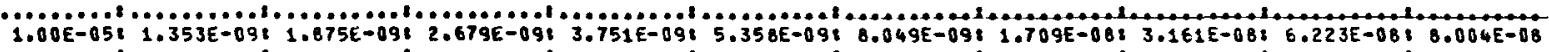

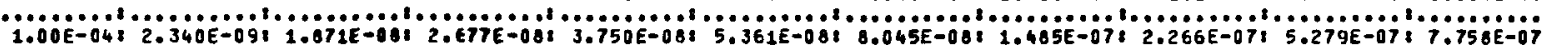

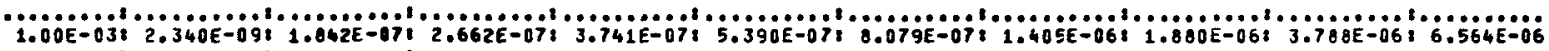

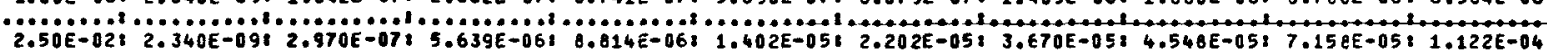

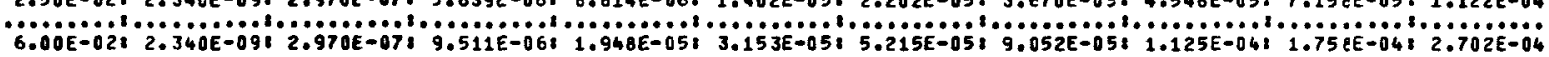

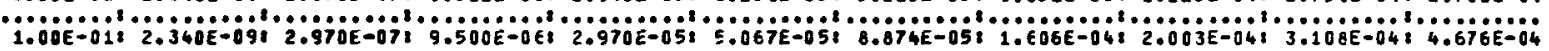

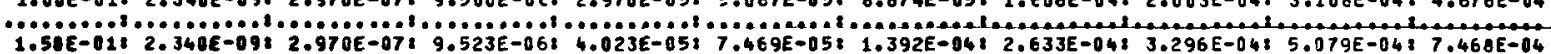

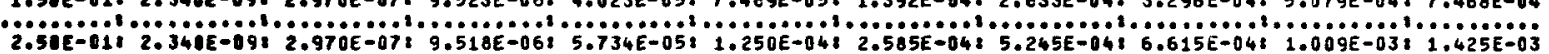

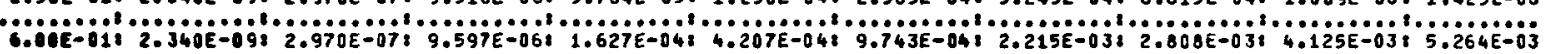

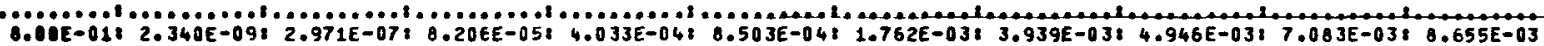

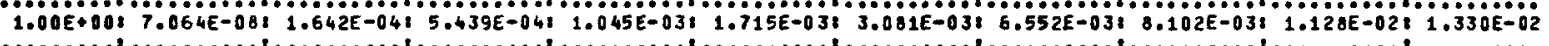

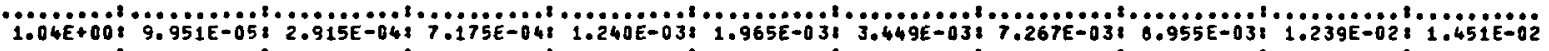

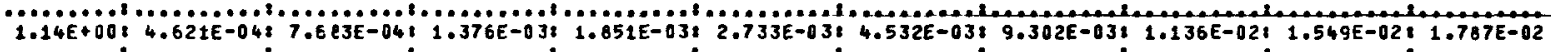
Ұ.25E+001

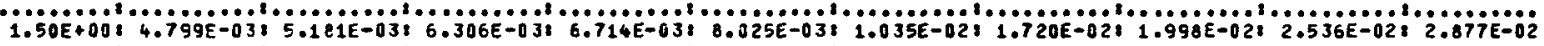

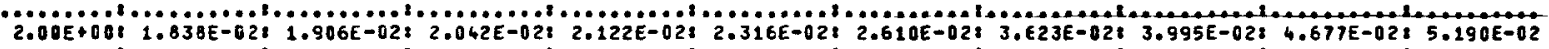

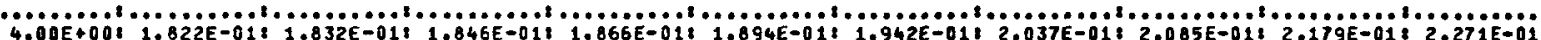

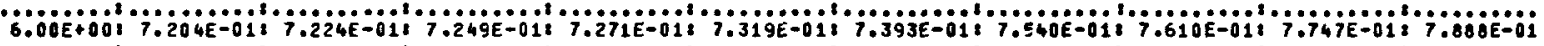

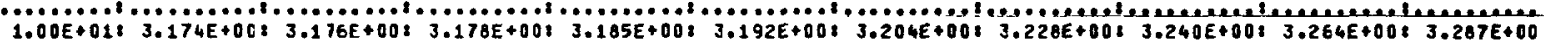

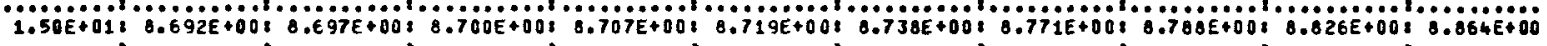

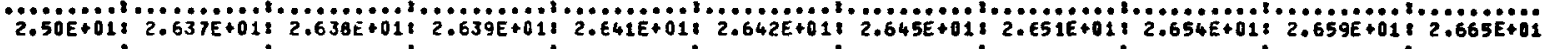
¥1.50E+021

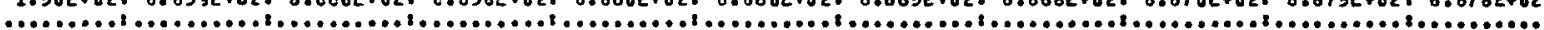
PRESSURE (TPA)

DENSITY I TEMPERATURE (EV)

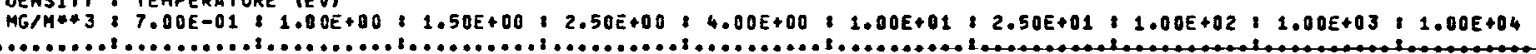

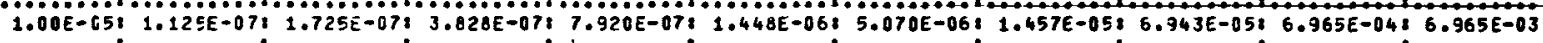

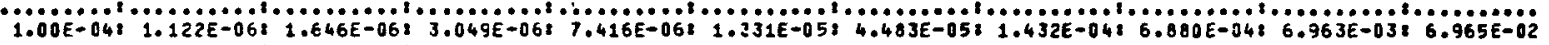

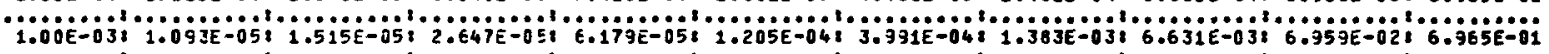

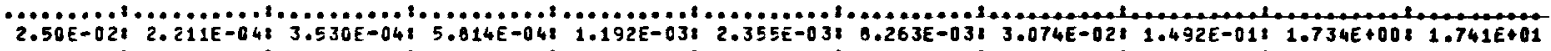
б.00Е-021 5.224Е-048

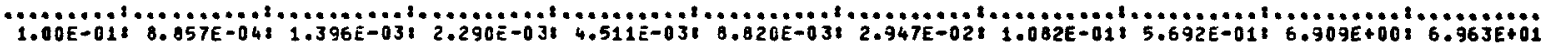

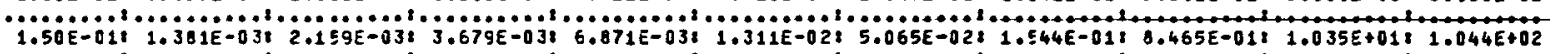

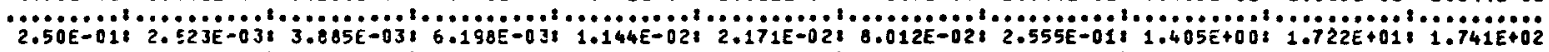

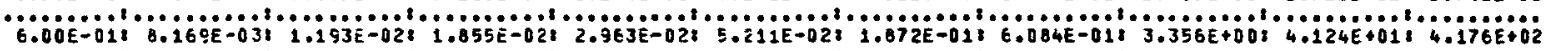

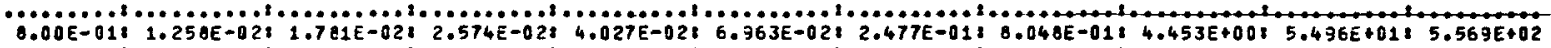

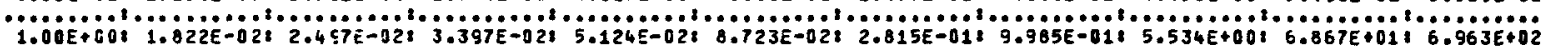
१.04Е+oq2

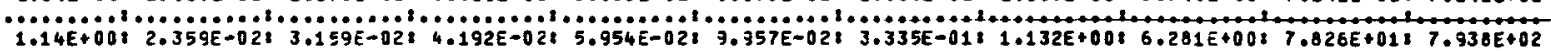

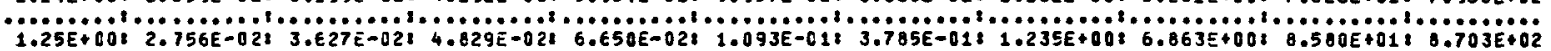

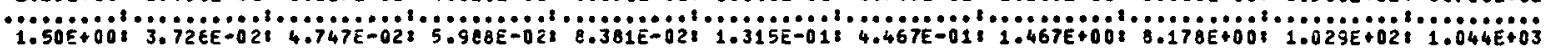

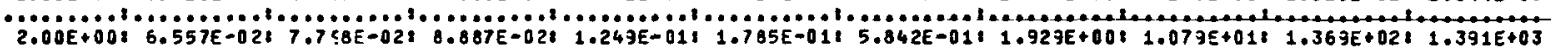

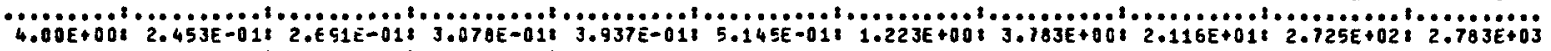

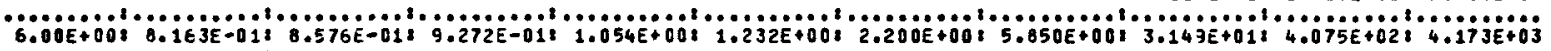

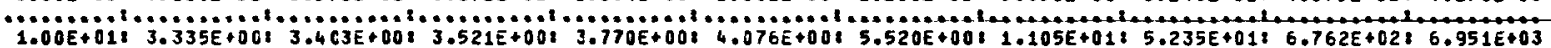

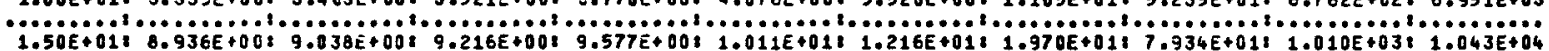

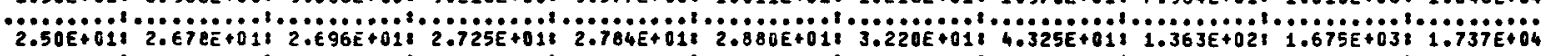
अ. $1.50 E+0218.882 E+028$
$\cdots$ 
Table 3. Values of $E$ at selected values of $T$ and $\rho$ (abstracted from the complete EOS table22).

DENSITY : TENPERATURE (EV)

$M G M * 3 ; 2.50 E-02: 3.50 E-02: 5.00 E-02: 7.00 E-02,1.00 E-01: 1.50 E-01: 2.50 E-01: 3.00 E-01: 4.00 E-01,5.00 E-01$

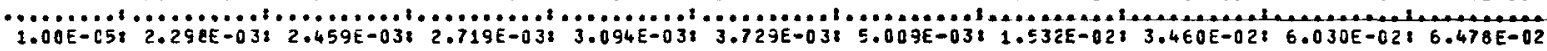

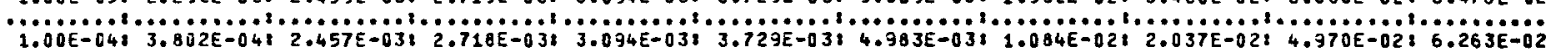

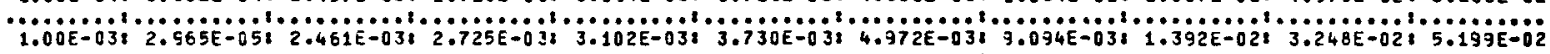

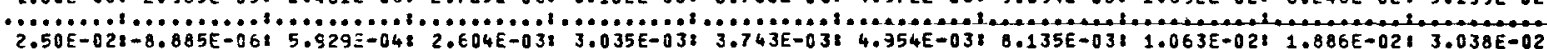

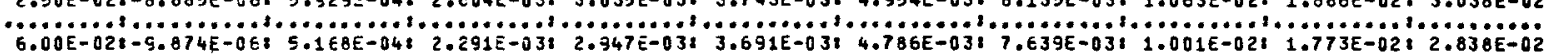

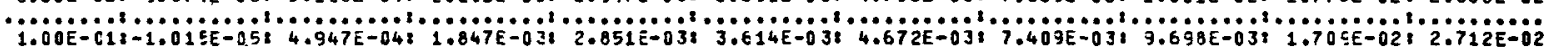

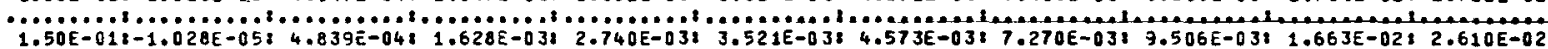

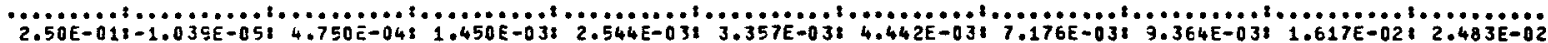

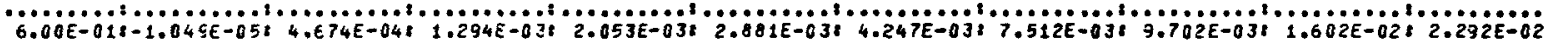

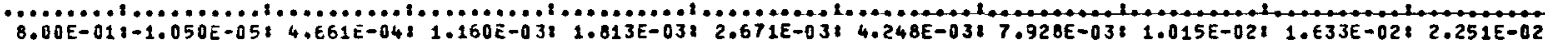

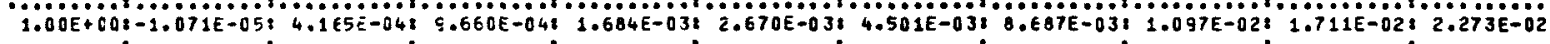

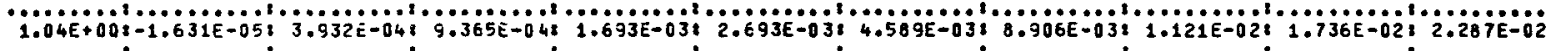

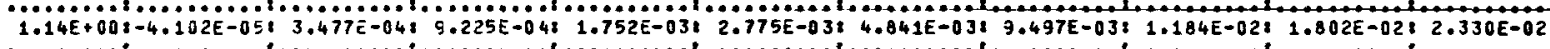

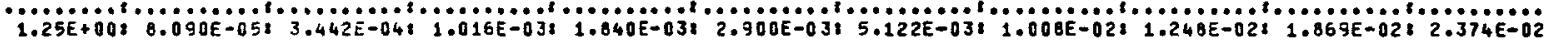

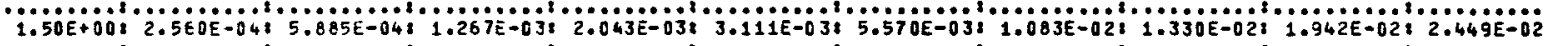

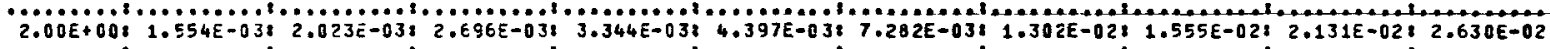

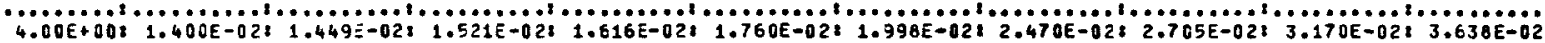

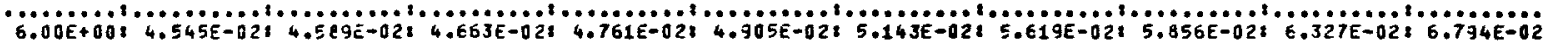

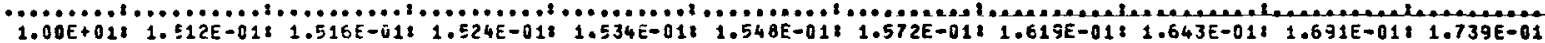

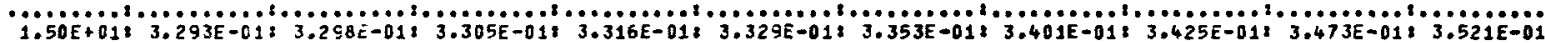

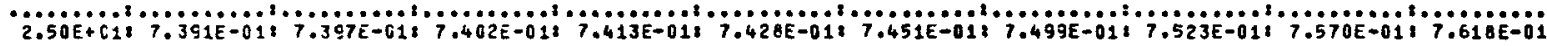

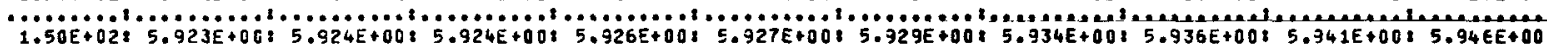

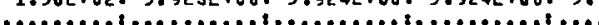

DENSITY TEMPERATURE IEVI

ENERGY $(M J / G)$

$M G / M+3: 7.00 E-01,1.00 E+00,1.50 E+00,2.50 E+00,4.00 E+00,1.00 E+01,2.50 E+01,1.00 E+02,1.00 E+03,1.00 E+04$

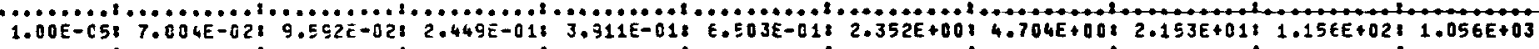
1.00Е-04, 6.984Е-0z,

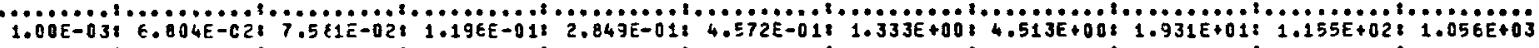

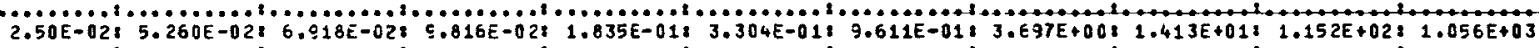

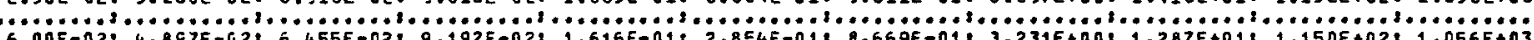

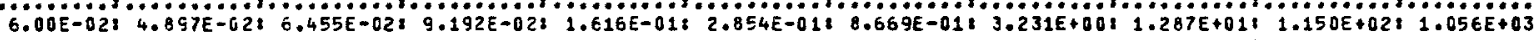
1.00E-01:

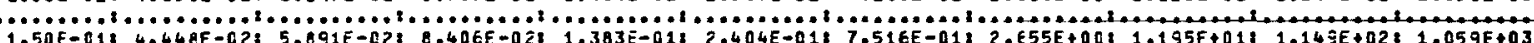

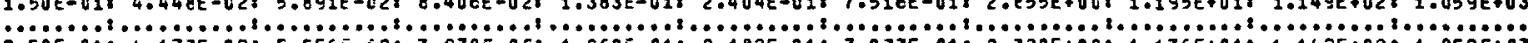

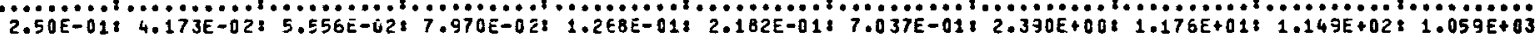

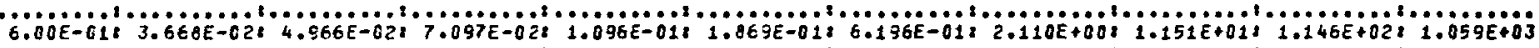

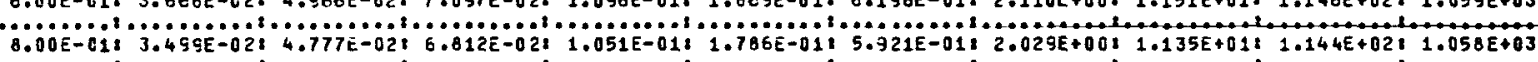

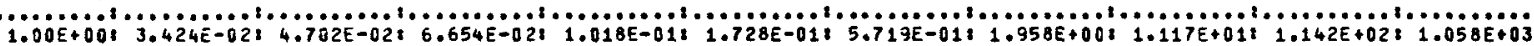

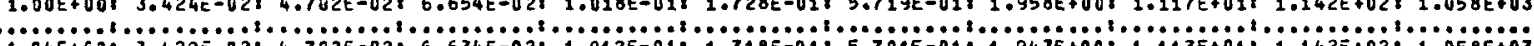

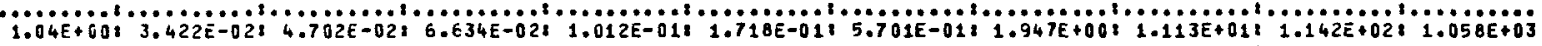

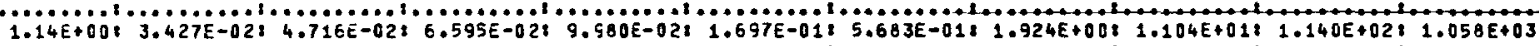

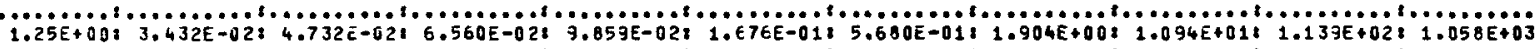
1.50E+

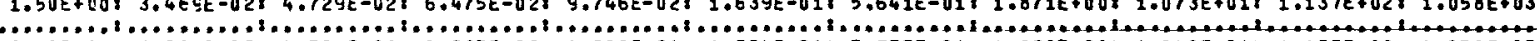

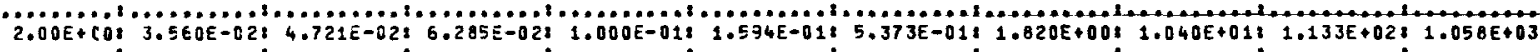

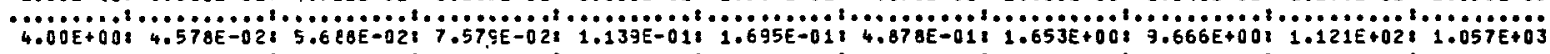

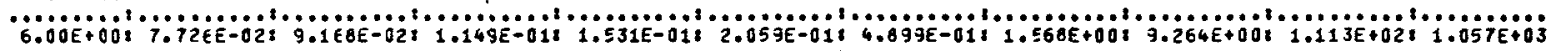

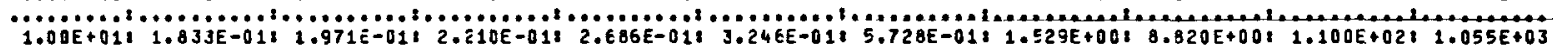

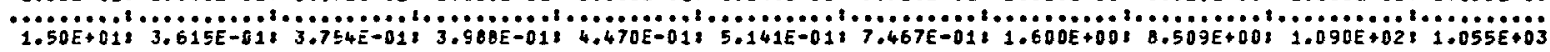

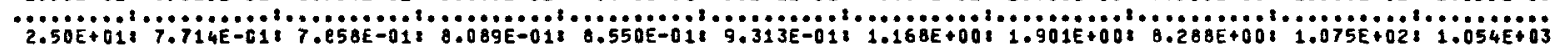

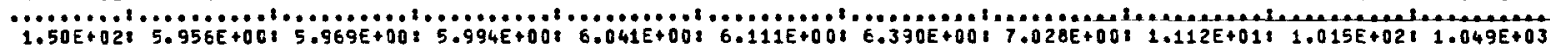

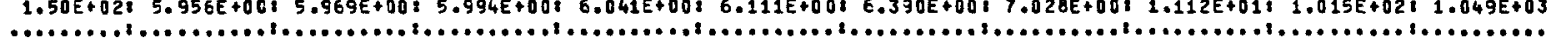


Fig. 4. The pressure vs energy isotherms over the steam region. There are 25 equally spaced isotherms from 293.15 to $773.15 \mathrm{~K}$.
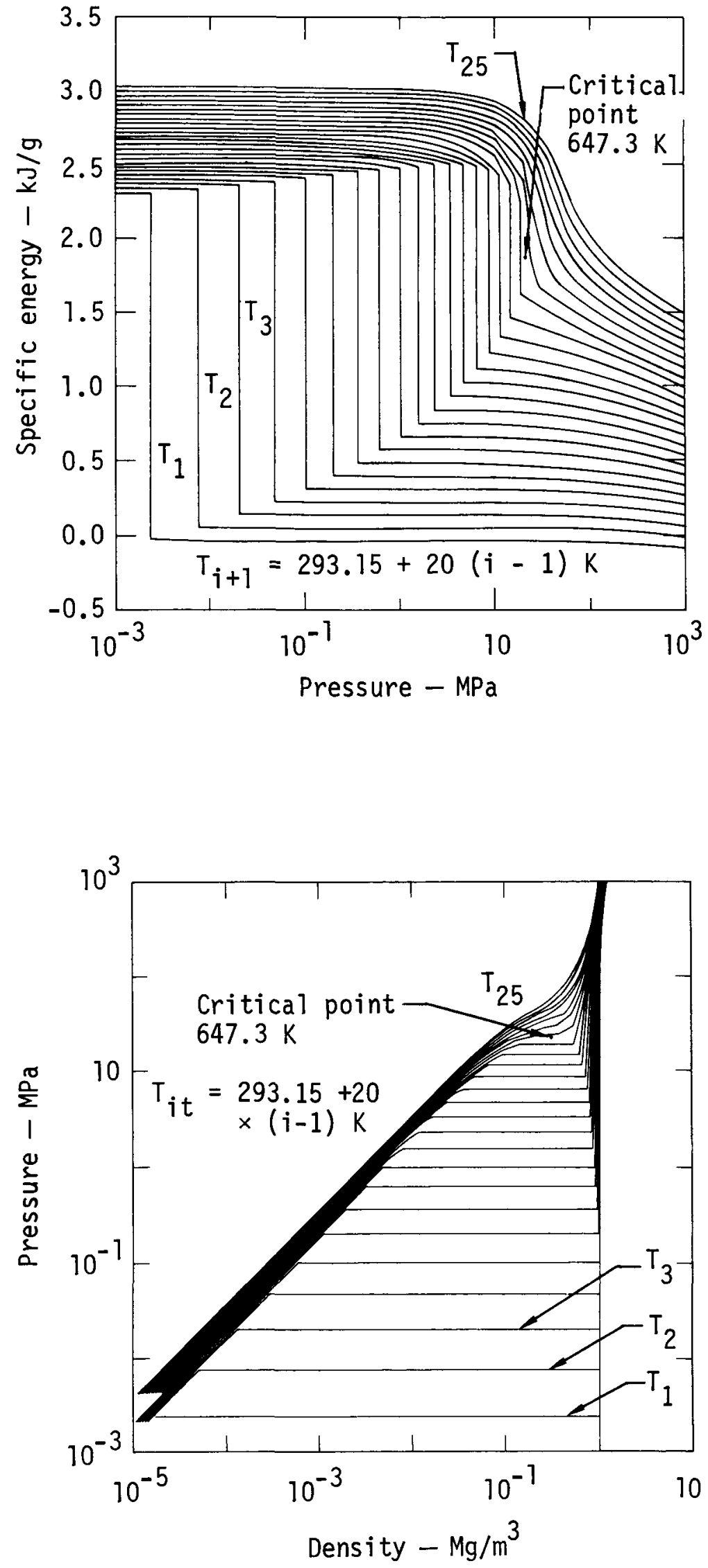
to describe the different $\rho-T$ subregions by assigning different values to the parameters in the expression. The form selected for this purpose is:

$$
P=(1+a \mu) \frac{G_{1}+G_{2} \varepsilon+G_{3} \varepsilon^{2}+G_{4} \varepsilon^{3}}{G_{5}+G_{6} \varepsilon+G_{7} \varepsilon^{2}},
$$

and

$$
G_{i}=\sum_{j=0}^{3} A_{i j} \mu^{j}
$$

where $\mathrm{P}$ is in $\mathrm{TPa}, \mu \equiv \rho / \rho_{0}-1, \varepsilon$ $(\mathrm{TPa}) \equiv \mathrm{E} \rho_{0}$, and $\rho_{0}=0.998 \mathrm{Mg} / \mathrm{m}^{3}$ (density at $298.15 \mathrm{~K}$ and standard pressure).

Coefficients $A_{i j}$ for two analytical expressions are presented in Tables 4 and 5 for the compression and expansion (mainly steam) regions of the water EOS, respectively. During the determination of $A_{i j}$, certain $A_{i j}$ 's are frozen at specified values. In Table 4, these frozen values are $A_{10}=0$ to yield $P=0$ at $\mu=\varepsilon=0$ as well as $\mathrm{A}_{11}=0.00219$ and $\mathrm{A}_{50}=$ 1.0 to correctly predict the bulk modulus at $\rho_{0}$ and $\varepsilon=0$. In Table 5

Table 4. Numerical values of constants $A_{i j}$ in the analytical expression [Eq. (7) with $a=1]$ used to $\mathrm{fit}^{1}$ the EOS data of water. ${ }^{\mathrm{a}}$

\begin{tabular}{lrrrr}
\hline$i$ & \multicolumn{1}{c}{$\mathrm{A}_{i 0}$} & $\mathrm{~A}_{\mathrm{i} 1}$ & $\mathrm{~A}_{i 2}$ & \multicolumn{1}{c}{$\mathrm{A}_{i 3}$} \\
\hline 1 & 0 & $2.190 \mathrm{E}-3$ & $1.544 \mathrm{E}-1$ & $2.160 \mathrm{E}-1$ \\
2 & $-1.340 \mathrm{E}-2$ & $2.809 \mathrm{E}+1$ & $1.990 \mathrm{E}+2$ & $-1.114 \mathrm{E}+1$ \\
3 & $1.493 \mathrm{E}+3$ & $3.016 \mathrm{E}+4$ & $7.418 \mathrm{E}+3$ & $3.184 \mathrm{E}+3$ \\
4 & $9.166 \mathrm{E}+4$ & $7.468 \mathrm{E}+5$ & $7.742 \mathrm{E}+4$ & $4.722 \mathrm{E}+3$ \\
5 & $1.000 \mathrm{E}+0$ & $6.723 \mathrm{E}+1$ & $-6.347 \mathrm{E}+1$ & $3.331 \mathrm{E}+1$ \\
6 & $1.625 \mathrm{E}+3$ & $3.274 \mathrm{E}+4$ & $-2.819 \mathrm{E}+3$ & $-1.842 \mathrm{E}+3$ \\
7 & $1.931 \mathrm{E}+5$ & $1.545 \mathrm{E}+6$ & $8.734 \mathrm{E}+4$ & $6.006 \mathrm{E}+3$ \\
\hline
\end{tabular}

$a_{\text {Range of applicability: }} 0.025 \leq \mathrm{T} \leq 10 \mathrm{eV}$ and $0.998 \leq \rho \leq 40 \mathrm{Mg} / \mathrm{m}^{3}$ and $\mathrm{P}$ $\leq 10^{-2} \mathrm{MPa}$. Note that $\mathrm{P}$ and $\varepsilon$ in $\mathrm{Eq} .(7)$ are expressed in $\mathrm{TPa}$. 
Table 5. Numerical values of constants $A_{i j}$ in the analytical expression [Eq. (7) with $a=0$ ] used to fit the EOS data of water in the principally liquid-vapor equilibrium range. ${ }^{a}$

\begin{tabular}{|c|c|c|c|c|}
\hline$i$ & $\mathrm{~A}_{i 0}$ & $A_{i 1}$ & $A_{i 2}$ & $A_{i 3}$ \\
\hline 1 & $1.0000000 \mathrm{E}-7$ & $-5.0893660 \quad E-8$ & 5.2838201 E-4 & $-3.9363072 \mathrm{E}-2$ \\
\hline 2 & -4.7273258 E-2 & $-9.0003238 E+0$ & $-1.0696594 E+2$ & $-9.5511199 E+3$ \\
\hline 3 & $-1.1611630 \mathrm{E}+4$ & $4.0721008 E+6$ & $6.3079416 \quad \mathrm{E}+7$ & $-1.1724779 E+9$ \\
\hline 4 & 7.2916356 E+9 & $3.6361684 \mathrm{E}+10$ & $-6.9116429 E+12$ & $-8.4530829 \mathrm{E}+13$ \\
\hline 5 & $1.0000000 \mathrm{E}+0$ & $-6.7953918 E+2$ & $3.0285599 \mathrm{E}+4$ & $-1.4200691 \mathrm{E}+7$ \\
\hline 6 & $-1.7224963 \mathrm{E}+6$ & $1.4444637 \mathrm{E}+8$ & $-2.4477486 E+10$ & 2.3300340 E+11 \\
\hline 7 & 4.2460639 E+11 & $1.1937554 \quad E+13$ & $4.0117326 \quad E+14$ & $-9.3774594 \quad E+14$ \\
\hline
\end{tabular}

a The range of applicability: $293.15 \leq \mathrm{T}<493.15 \mathrm{~K}, 0.699 \leq \rho \leq 1.002 \mathrm{Mg} / \mathrm{m}^{3}$, and $2.2 \times 10^{-3} \leq \mathrm{P} \leq 3.0 \mathrm{MPa}$. Note that $\mathrm{P}$ and $\varepsilon$ in Eq. (7) are in TPa.

$A_{10}=10^{-7}$ and $A_{50}=1.0$ are fixed to produce the correct standard pressure at $\varepsilon=0$. The $A_{i j}$ parameters given in Table 4 can be used for $T$ between 0.025 and $10 \mathrm{eV}$ and for $\rho$ between $\rho_{0}$ and $40 \mathrm{Mg} / \mathrm{m}^{3}$ (corresponding to $\mathrm{P} \leq 80 \mathrm{TPa})$. Summing $\mid \mathrm{P}$ (analytic fit/P(data point) - I| over 549 data points at $\mathrm{P}>0.1 \mathrm{MPa}$, the average error is $2.6 \%$. The expression given in Table 5 is developed for the reactor-safeguarding analysis and therefore, is applicable only within a small density $\left(0.7 \rho_{0}-1.004 \rho_{o}\right)$ and temperature $(293.15$ - $493.15 \mathrm{~K})$ range corresponding to $\mathrm{P} \leq 3 \mathrm{MPa}$. Here, the average error over 368 data points is $7.5 \%$. The above-mentioned $\rho-T$ range includes the high-density portion of the liquid-vapor region where $P$, at a fixed value of $T$, is flat and independent of density. The $\rho-T$ range also includes the purely liquid portion where $P$ increases abruptly. Strictly speaking, any analytical expression for $P$ cannot "turn the corner" as abruptly as is observed in the real isotherms. Nevertheless, the expression given in Table 5 can approximately satisfy such a requirement.

\section{PRINCIPAL HUGONIOT}

Hugoniots of water with an initial state at room temperature and standard pressure have been measured by Walsh and Rice 19 to $42 \mathrm{GPa}$ and by Skidmore and Morris to about $110 \mathrm{GPa}$ (see 
Ref. 20). The experimental Hugoniot data are plotted in Fig. 6 for $U_{p}$ vs $U_{s}$ and $\rho$ vs $P$. The corresponding Hugoniots derived from our present work are also shown. The theoretical Hugoniot was obtained by solving for $\rho$ which satisfies the Rankine-Hugoniot relation along each isotherm in the EOS table, i.e.,

$$
H=E-E_{o h}-\left(P+P_{o h}\right)\left(V_{o h}-V\right) / 2=0,
$$

where the initial point ( $E_{o h}, P_{o h}$ ' $\mathrm{V}_{\mathrm{oh}}$ ) corresponds to $\mathrm{E}_{\mathrm{oh}}=\mathrm{P}_{\mathrm{oh}}=0$ and $\mathrm{v}_{\text {oh }}=\mathrm{v}_{\mathrm{o}}=1.002 \mathrm{~m}^{3} / \mathrm{Mg}$. The theoretical Hugoniot follows very closely Walsh and Rice's experimental points 19 to about $13 \mathrm{GPa}$. Above this point (especially above $100 \mathrm{GPa}$ ), the experimental points have large uncertainties. Both the experimental and theoretical points can be considered to agree within the experimental uncertainties. There is a lack of experimental data between 4 and $8 \mathrm{~km} / \mathrm{s}$ in $U_{p}$ or between 42 and $100 \mathrm{GPa}$ in $\mathrm{P}$. Hugoniot experiments to obtain these necessary data are being prepared by Nellis and Shaner. ${ }^{23}$ Such experiments will provide data with which to test

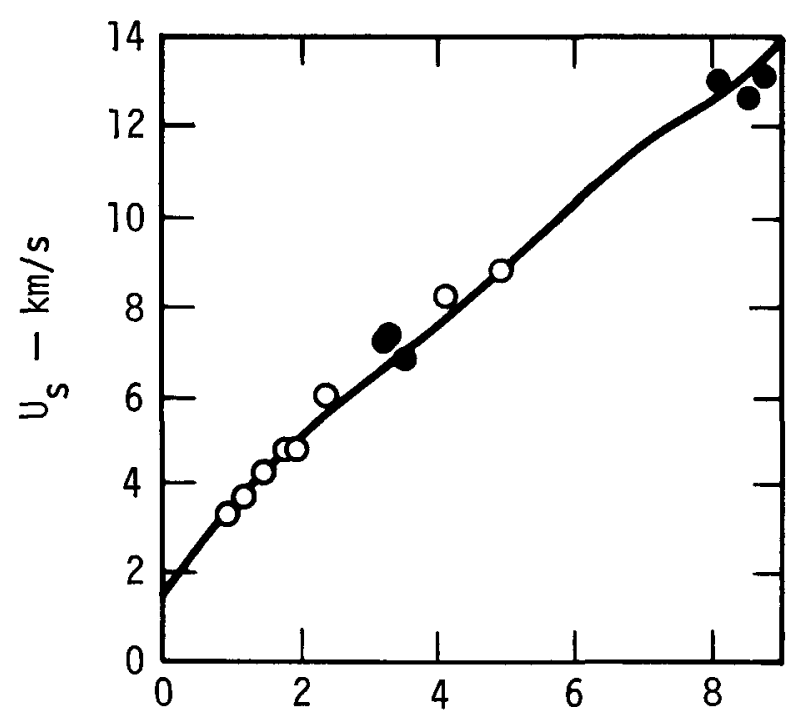

(a)

$$
U_{p}-k m / s
$$

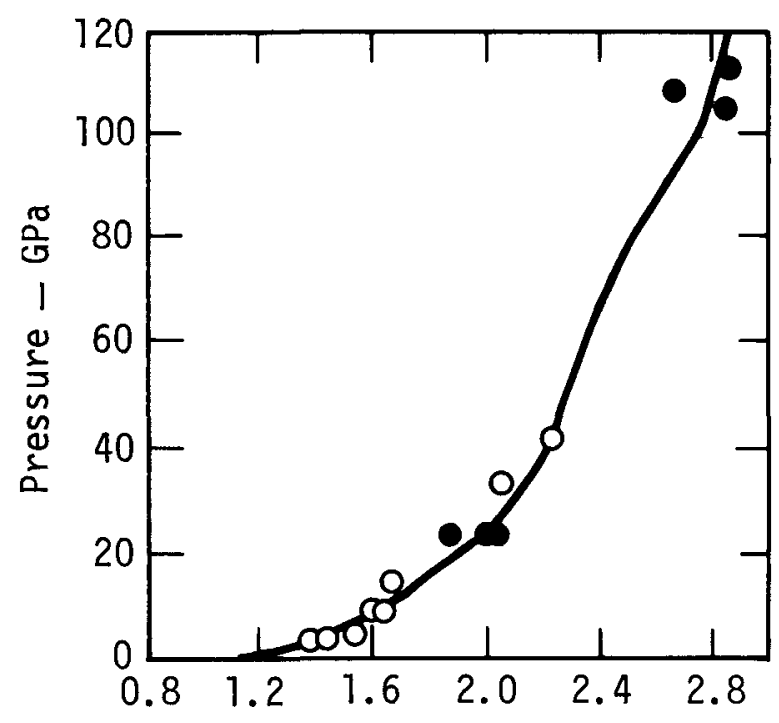

(b)

Fig. 6. The principal Hugoniot of steam: (a) $U_{S}$ vs $U_{P}$ and (b) $P$ vs $\rho$. Open circles are experimental data of Walsh and Rice ${ }^{19}$, solid circles are data of Skidmore and Morris ${ }^{20}$, and the curve represents our calculations. 
the adequacy of our present work. The available experimental data near 1.4 to $3 \mathrm{Mg} / \mathrm{m}^{3}$ lie well within the hole region that connects the EXPERIMENTAL and MASTER regions (see Fig.

1). The satisfactory agreement between the theoretical and experimental data, therefore, indicates that the procedure used to interpolate the EOS data in this most difficult hole region was apparently successful.

HUGONIOT OF STEAM: HIGH-PRESSURE PORTION

To our knowledge, experimental shock-wave data on steam are not available in the literature. This is unfortunate because steam undergoes an enormous volume change under shock compression. This in turn produces a large increase in internal energy and results in a high temperature. Accordingly, if accurate Hugoniot measurements are made, they would offer a valuable tool with which to probe the thermodynamic behavior of water in the chemically reacting region and possibly in the partially ionizing regime for higher-pressure experiments. Such experiments could be conducted with a two-stage gas gun. Preliminary feasibility studies on such experiments are in progress by Gust and Shaner. 24

To estimate the magnitudes of dynamic and thermodynamic variables achieved along such Hugoniots, we have conducted Hugoniot calculations using our water EOS table. Three different initial states are considered. These points lie on the saturated-vapor 1 ine at $\mathrm{T}_{\mathrm{oh}}=0.0339$, 0.0470 , and $0.0522 \mathrm{eV}$ (corresponding respectively to $\mathrm{P}_{\text {oh }}=0.2,0.5$, and $2 \mathrm{MPa}$ or, equivalently, to $\mathrm{V}_{\mathrm{oh}}=$ $885.4,374.7$, and $99.54 \mathrm{~m}^{3} / \mathrm{Mg}$ ). Plots of $T$ vs $\rho, P$ vs $\rho$, and $U_{s}$ vs $U_{p}$ along the Hugoniots are shown in Fig. 7. Compressions achieved in the initial

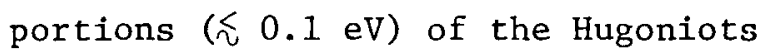
in Fig. $7(\mathrm{a}, \mathrm{b})$ are mainly associated with the $P \triangle V$ work and the excitation of the rotational degrees of freedom. The subsequent compressions to about $0.3 \mathrm{eV}$ (Fig. 7c) result from the excitation of the internal vibrations of $\mathrm{H}_{2} \mathrm{O}$ molecules that soak up the energy and reduce the temperature increase. At higher temperatures, the stored vibrational energy becomes so large that $\mathrm{H}_{2} \mathrm{O}$ molecules break apart partially or completely, thereby forming mixtures of reacting species in a chemical equilibrium. Maximum compressions achieved in the present problems are eleven- to fourteen-fold greater than the initial densities. Temperatures at these points are about $0.5 \mathrm{eV}$ and the values of Grineisen $\gamma$ are 0.15 to 0.2 . To experimental1y realize such compressions, it is necessary to generate a shock wave in 


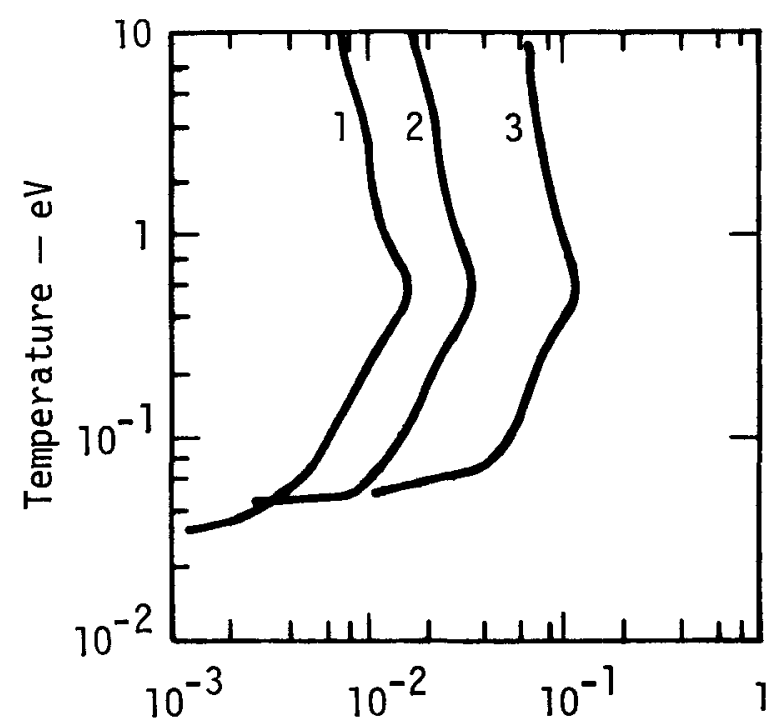

(a) Density $-\mathrm{Mg} / \mathrm{m}^{3}$

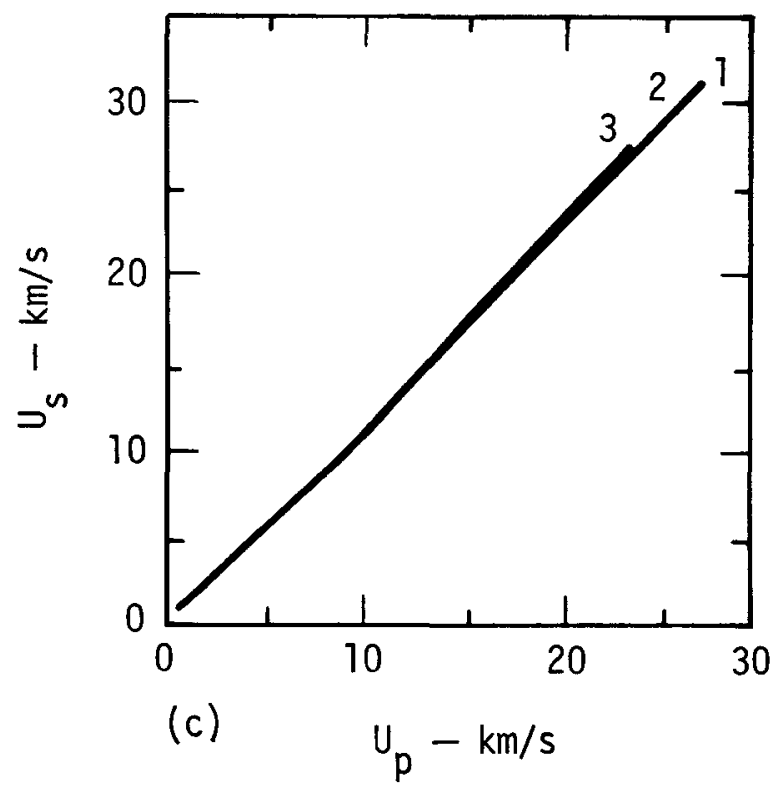

water with $\mathrm{U}_{\mathrm{s}} \simeq 7.7$ to $8.4 \mathrm{~km} / \mathrm{s}$ (corresponding to $U_{\mathrm{p}} \approx 7.0$ to $7.8 \mathrm{~km} / \mathrm{s}$ ). The slopes of $(\partial P / \partial \rho)_{H}$ change sign beyond these compressions because the temperatures attained are high enough for the reacting species to begin to exhibit more ideal-gaslike

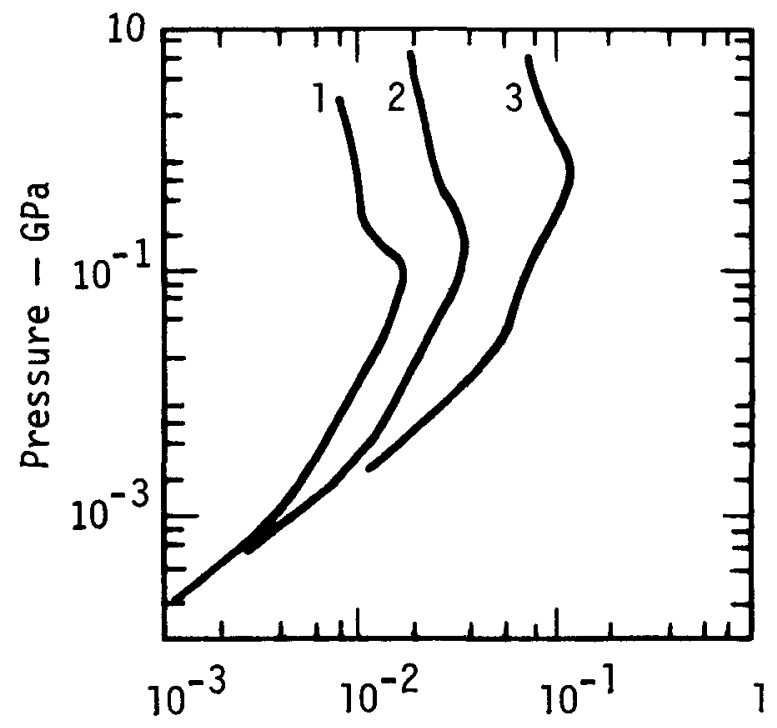

(b) Density $-\mathrm{Mg} / \mathrm{m}^{3}$

Fig. 7. Hugoniot of steam with the initial state lying on the saturatedvapor line at $\mathrm{P}_{\mathrm{oh}}=0.2,0.5$, and $2 \mathrm{MPa}$ (or equivalent $1 \mathrm{y}$ at $\mathrm{T}_{\mathrm{oh}}=$ $0.0339,0.0470$, and $0.0522 \mathrm{eV}$ ) and represented by lines 1,2 , and 3 , respectively: (a) $\mathrm{T}$ vs $\rho$, (b) $\mathrm{P}$ vs $\rho$, and (c) $U_{s}$ vs $U_{p}$. behavior. At sufficiently high $T$, the volume compressions approach the ideal-gas value of $1 / 4$ of the initial volumes.

The relative abundances of the chemical species along the Hugoniot trajectory, starting at $\mathrm{P}_{\text {oh }}=0.2 \mathrm{MPa}$, 
are shown in Fig. 8. At $\mathrm{T}$ of 0.3 to $0.4 \mathrm{eV}, \mathrm{H}_{2} \mathrm{O}$ molecules dissociate into molecular hydrogen $\left(\mathrm{H}_{2}\right)$ and hydroxyl $(\mathrm{OH})$ radical that is highly reactive and usually occurs as a transient intermediate. At even higher temperatures up to $1.0 \mathrm{eV}$, other dissociation products $\left(\mathrm{H}, \mathrm{O}, \mathrm{O}_{2}\right)$ appear significantly. However, above $\mathrm{T} \geq 1.0 \mathrm{eV}$, only hydrogen and oxygen atoms exist in any significant amount.

HUGONIOT OF STEAM: LOW-PRESSURE PORTION

Another region where shock Hugoniots exhibit interesting behavior is located at temperatures below $0.1 \mathrm{eV}$, in the steam "dome" region where the liquid-vapor transition occurs. Within this region, accurate thermodynamic data are available from the steam table as well as from calorimetric and hydrostatic measurements. Comparison of dynamic and static data in the liquid-vapor transition region provides information on rate effects associated with the formation and evaporation of liquid droplets. Present shock-tube techniques are sufficiently advanced so that it may be possible to actually perform such experiments.

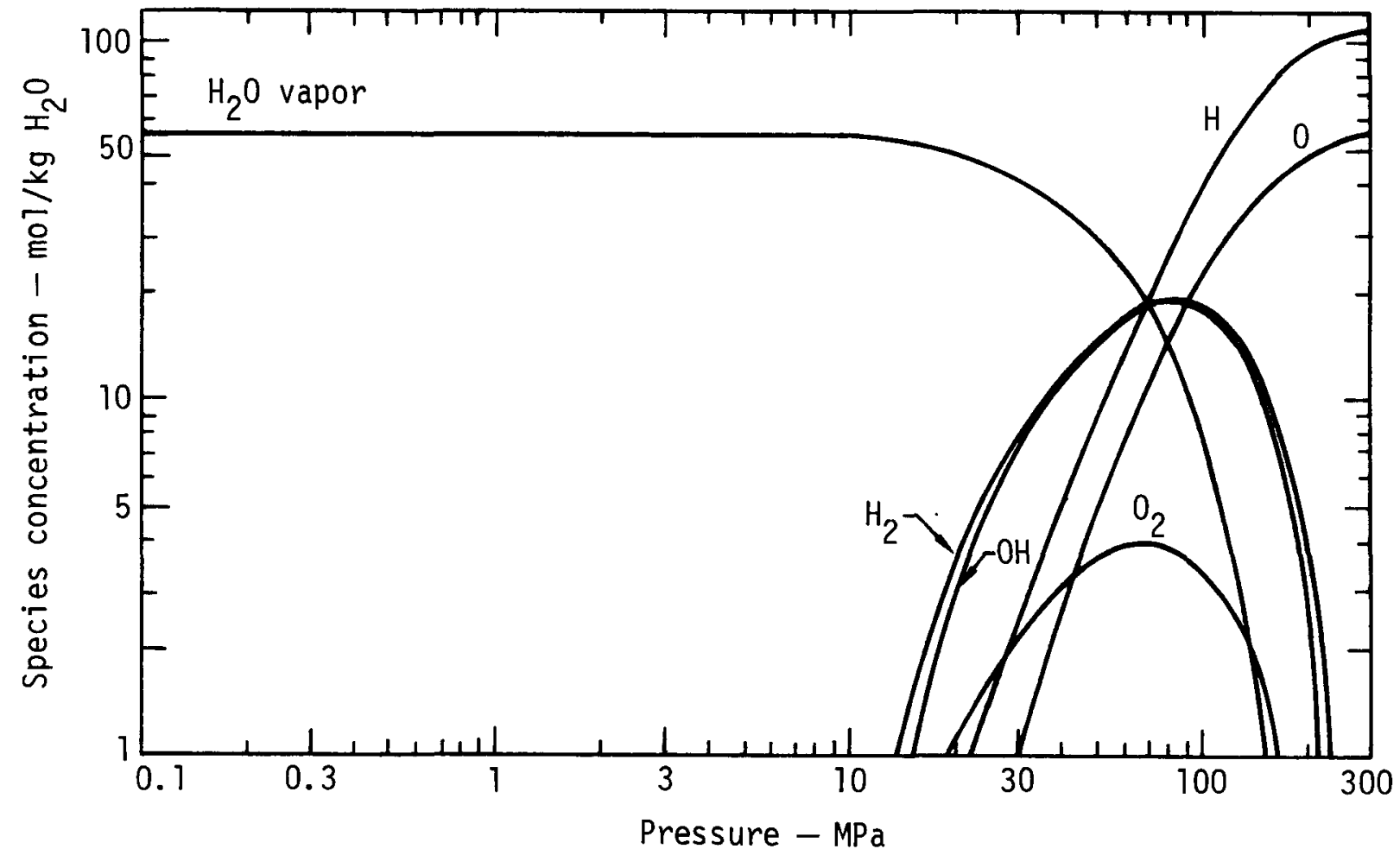

Fig. 8. Relative abundance of the chemical species that occur along the Hugoniot trajectory shown in Fig. 7 (initial point $\mathrm{P}_{\text {oh }}=0.2 \mathrm{MPa}$ ). 
Within the two-phase region, two energetic processes essentially control the trajectory of a Hugoniot. These are the $P \Delta V$ work that is associated with the volume compression and the energy release during the condensation of steam. Depending on the location of the initial state, one process can predominate over the other to determine the subsequent trajectory. The $\mathrm{P} \Delta \mathrm{V}$-work process dominates if $\mathrm{E}$ is appreciably larger than $E_{o h}$ and if $E$ is approximately balanced by the P $\Delta \mathrm{V}$ term in Eq. (9). The energy-release process becomes important when the initial state $\left(\mathrm{V}_{\mathrm{oh}}\right.$, $\mathrm{T}_{\mathrm{oh}}$ ) lies close to the saturatedvapor line. In this case, $E_{o h}$ is relatively larger than the corresponding energy on the pure liquid side. The Hugoniot compression induces the partial condensation of steam, thereby releasing the energy stored in the vapor. Here, the Hugoniot condition [Eq. (9)] is essentially satisfied by a near cancellation of $\mathrm{E}_{\mathrm{oh}}$ and $\mathrm{E}$ in Eq. (9); the contribution of the $\mathrm{P} \triangle \mathrm{V}$ term affects the Hugoniot solution in only a minor way.

To rigorously study the situations described above, we employed the experimental data ${ }^{2,3}$ and examined the possible Hugoniot trajectories originating from three different volumes, $\mathrm{V}_{\text {oh }}=1000,10$, and $3.333 \mathrm{~m}^{3} / \mathrm{Mg}$, and from four different temperatures,
$\mathrm{T}_{\text {oh }}=0.0511,0.0373,0.0321$, and $0.0253 \mathrm{eV}$ (corresponding to 593.15, 433.15, 373.15, and $293.15 \mathrm{~K}$ ). Hugoniot plots of $T$ vs $\rho, P$ vs $\rho$, and $U_{s}$ vs $U_{p}$ are shown in Fig. 9 for $\mathrm{V}_{\text {oh }}=1000 \mathrm{~m}^{3} / \mathrm{Mg}$. The corresponding data for $\mathrm{V}_{\mathrm{oh}}=10$ and $3.333 \mathrm{~m}^{3} / \mathrm{Mg}$ are shown in Figs. 10 and 11, respectively. The initial states in Fig. $9\left[\left(\mathrm{~V}_{\mathrm{oh}}, \mathrm{T}_{\mathrm{oh}}\right)=(1000,0.0511)\right.$ and $(1000,0.0373)]$ lie in the purevapor phase. The other initial states in Figs. 9-11 belong to the coexistence region. Several interesting features are revealed by these figures:

(1) If the initial state of a Hugoniot lies within the twophase region and if its density is not close to the saturation density of vapor, the Hugoniot locus enters immediately into the pure-1iquid-water phase. (See curve 4 in Fig. 9b, curves 2 and 3 in Figs. $10 \mathrm{~b}$ and 11b).

(2) The Hugoniots belonging to those with the lowest initial density (namely, Hugoniots 3 and 4 in Fig. 9b) subsequent $1 y$ reenter the two-phase region at a higher pressure. Eventually, they exit the coexistence region through the vapor side. Those Hugoniots belonging to (1) with the intermediate initial density (namely, those in Fig. 10b) stay 


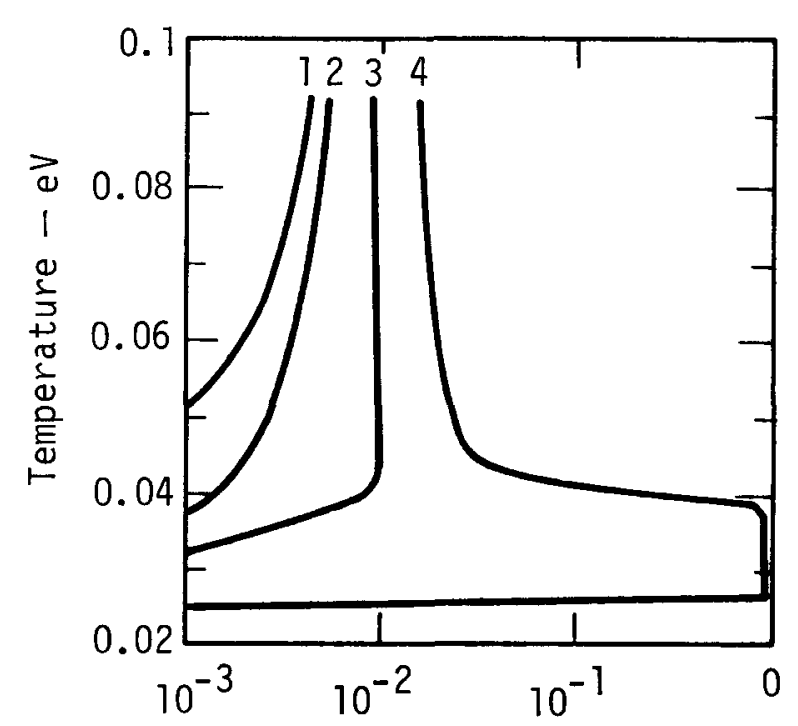

(a) Density $-\mathrm{Mg} / \mathrm{m}^{3}$

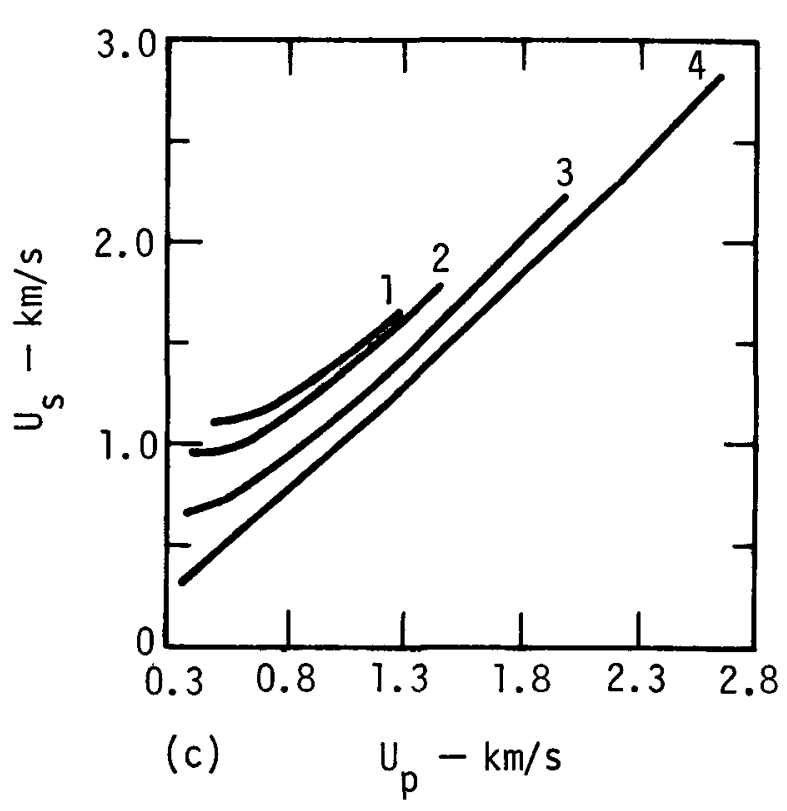

within the liquid phase, eventually bending back toward lower densities at a pressure above the critical-point pressure and thereby completely bypassing the two-phase region. Those Hugoniots with the highest initial

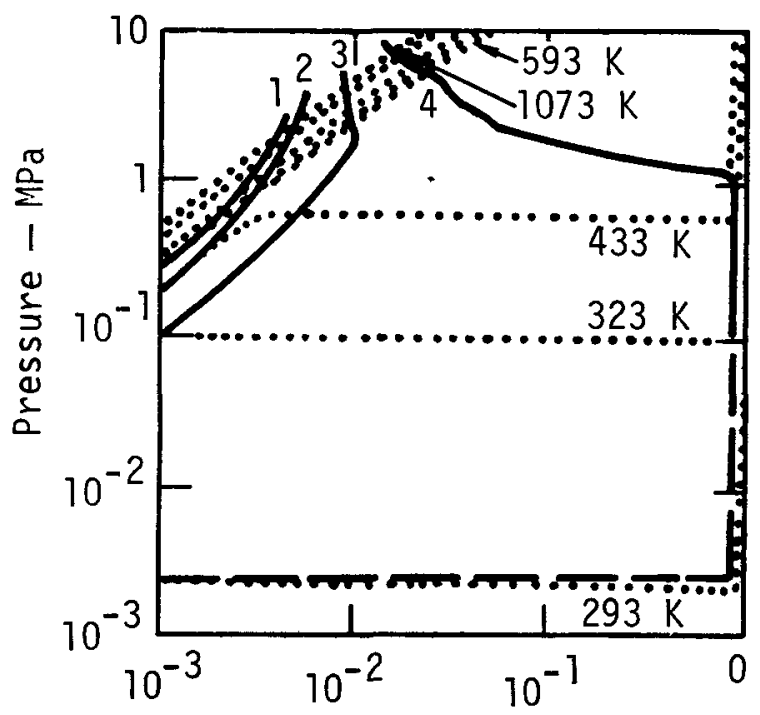

(b) Density $-\mathrm{Mg} / \mathrm{m}^{3}$

Fig. 9. Low-temperature Hugoniots of steam starting at $\mathrm{V}_{\mathrm{oh}}=1000 \mathrm{~m} 3 / \mathrm{Mg}$ and at initial temperatures of $0.0522,0.0373,0.0321$, and $0.0253 \mathrm{eV}$ (Hugoniots $1,2,3$, and 4, respective1y): (a) T vs $\rho$, (b) $P$ vs $\rho$, and (c) $U_{s}$ vs $U_{p}$. The initial states of Hugoniots 1 and 2 lie outside the liquid-vapor transition region while the initial states of Hugoniots 3 and 4 lie inside the transition region. Note that some isotherms (dotted 1ines) are superimposed in (b) to indicate the Hugoniot trajectories. Portions of the Hugoniots in (b) indicated by dash-dotted lines are obtained by interpolation between the highpressure points and the initial points.

density (Fig. 11b) behave "normally" as the pressure increases with increasing density.

The Hugoniot in (1) penetrates deeply into the pure-liquid phase if the initial temperature is low or if the initial density is high. In fact, 


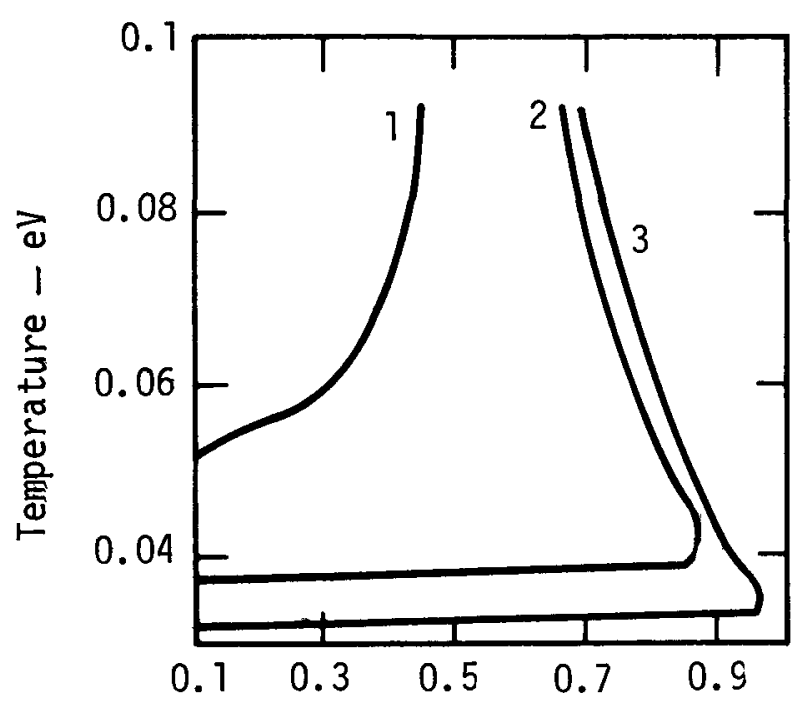

(a) Density $-\mathrm{Mg} / \mathrm{m}^{3}$

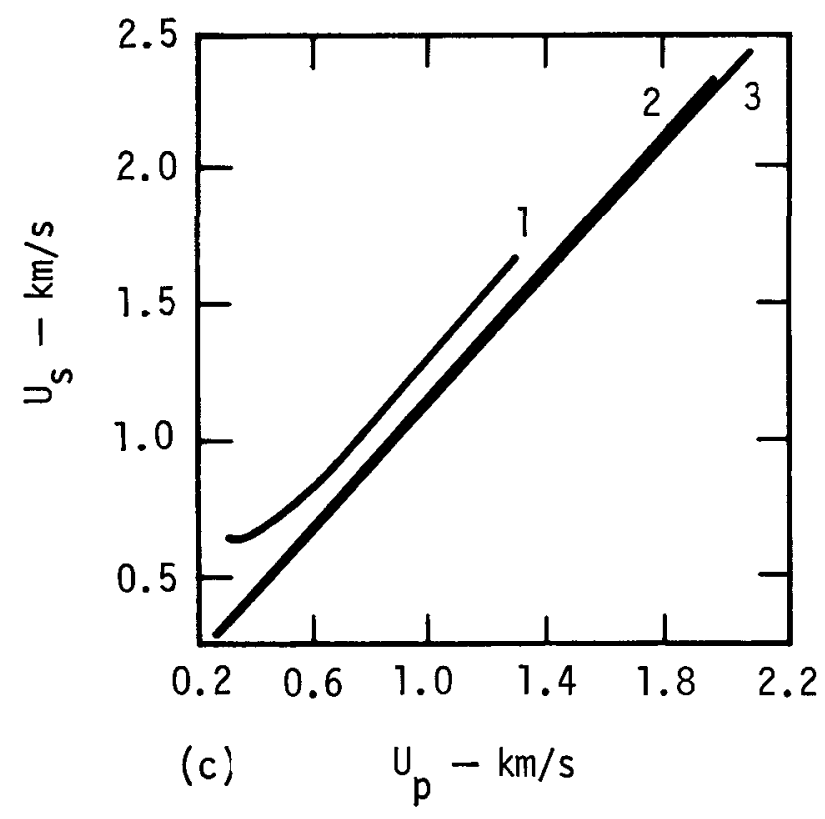

the Hugoniot states that immediately follow the initial states $\left[\mathrm{T}_{\mathrm{oh}}=\right.$ $0.025 \mathrm{eV}$ and $\mathrm{V}_{\text {oh }}=10 \mathrm{~m}^{3} / \mathrm{Mg}$ ) and $\left(\mathrm{T}_{\mathrm{ob}}=0.025 \mathrm{eV}\right.$ and $\left.\left.3.333 \mathrm{~m}^{3} / \mathrm{Mg}\right)\right]$ penetrate so deep1y into the pureliquid region that they exceed the boundary of the experimental data which ends at $\rho=1.2 \mathrm{Mg} / \mathrm{m}^{3}$ (i.e. $20 \%$

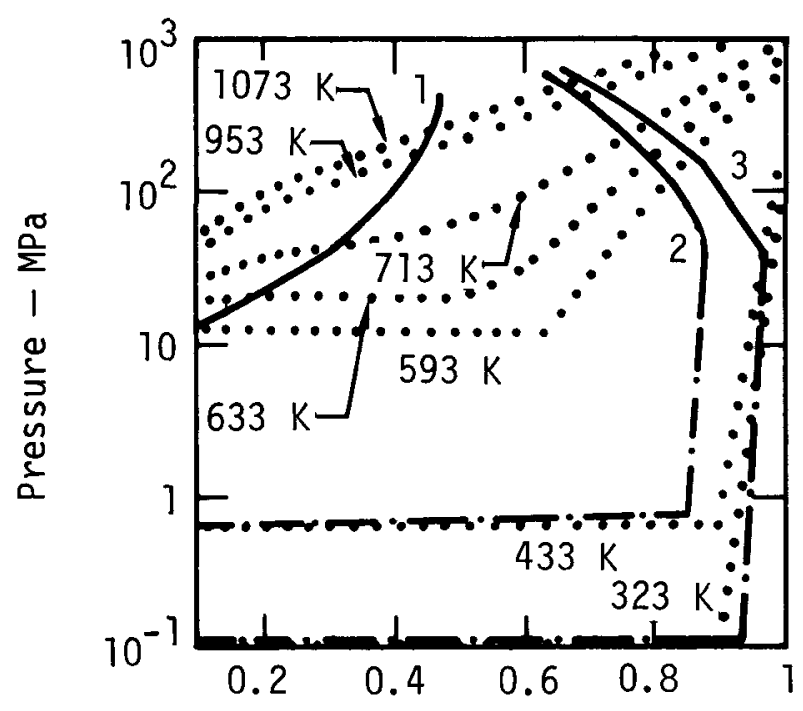

(b) Density $-\mathrm{Mg} / \mathrm{m}^{3}$

Fig. 10. Low-temperature Hugoniots of steam starting at $\mathrm{V}_{\mathrm{oh}}=10 \mathrm{~m}^{3} / \mathrm{Mg}$ and at initial temperatures of 0.0522 , 0.0373 , and $0.0321 \mathrm{eV}$ (Hugoniots 1 , 2 , and 3 , respectively): (a) $T$ vs $\rho$, (b) $P$ vs $\rho$, and (c) $U_{s}$ vs $U_{p}$. A11 initial states lie within the two-phase region. Note that some isotherms (dotted lines) are superimposed in (b) to indicate the Hugoniot trajectories. Portions of the Hugoniots in (b) indicated by dash-dotted lines are obtained by interpolation between the highpressure points and the initial points. compression of water at standard state at room temperature). Therefore, we were not able to present these Hugoniots in Figs. 10 and 11.

The peculiar behavior described in (1) is not difficult to understand. The vapor pressure can be extremely sma11, behaving like vexp(-constant/ 


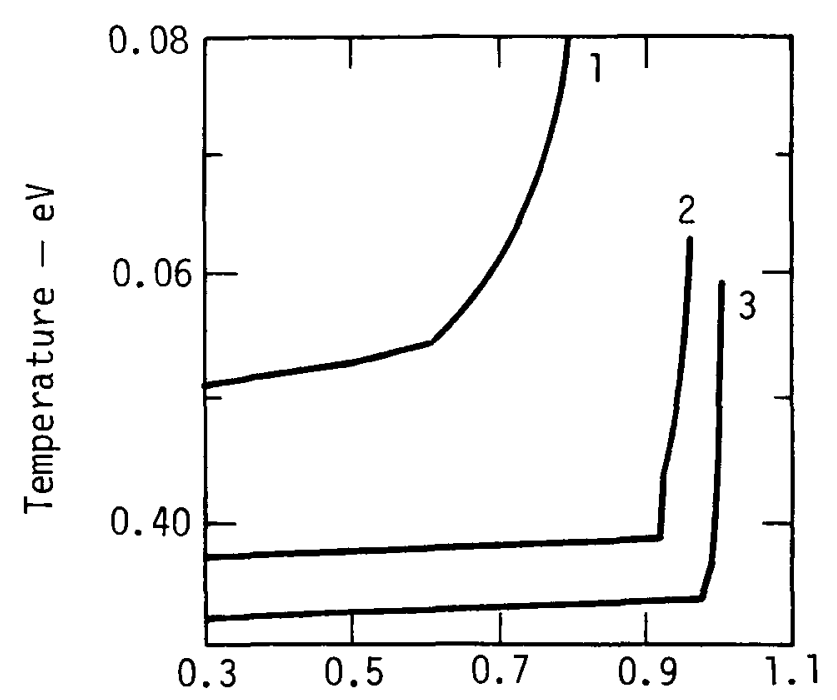

(a) Density $-\mathrm{Mg} / \mathrm{m}^{3}$

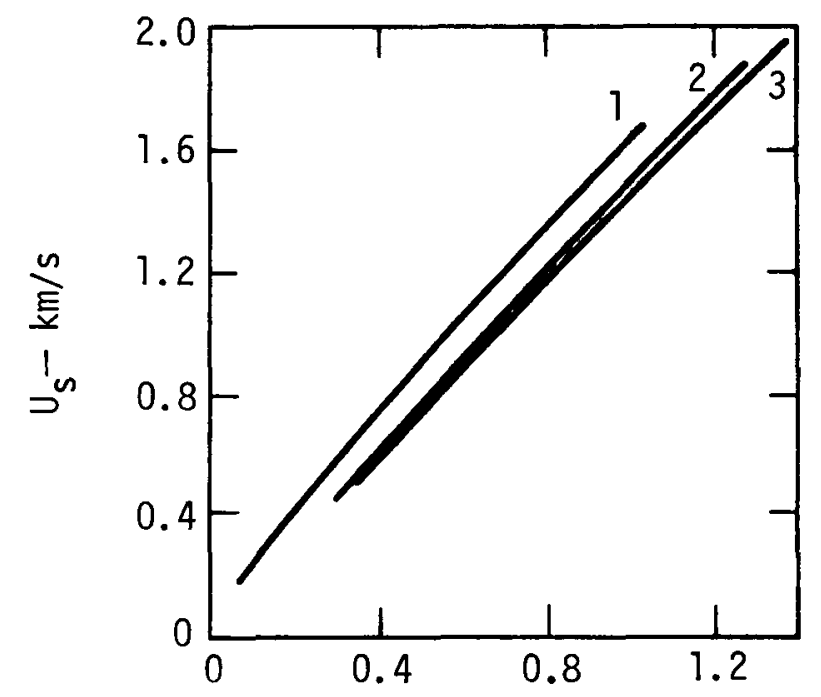

(c)

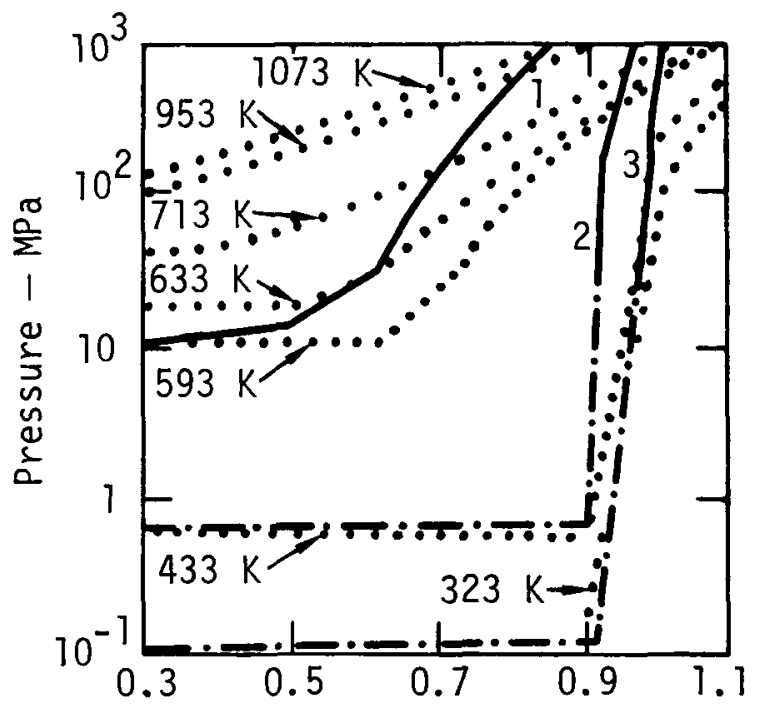

(b) Density $-\mathrm{Mg} / \mathrm{m}^{3}$
Fig. 11. Low-temperature Hugoniots of steam starting at $\mathrm{V}_{\mathrm{oh}}=3.333 \mathrm{~m}^{3} / \mathrm{Mg}$ and at temperatures of $0.0522,0.0373$, and $0.0321 \mathrm{eV}$ (Hugoniots 1, 2, and 3 , respectively): (a) $\mathrm{T}$ vs $\rho$, (b) $P$ vs $\rho$, and (c) $U_{s}$ vs $U_{p} \cdot A 11$ initial states lie within the twophase region. Note that some isotherms (dotted lines) are superimposed in (b) to indicate the Hugoniot trajectories. Portions of the Hugoniots in (b) indicated by dash-dotted lines are obtained by interpolation between the highpressure points and the initial points.
$\mathrm{T})$ at low $\mathrm{T}$ and is independent of $\rho$. Moreover, within the two-phase range, $E$ also is nearly a constant along an isotherm if $\mathrm{V}_{\mathrm{oh}} \ll \mathrm{V}_{\mathrm{g}}$. Therefore, $E-E_{o h}$ is nearly constant but is much larger than the $\mathrm{P} \Delta \mathrm{V}$ term in the

\begin{abstract}
Hugoniot relation within the twophase region even for those states that immediately follow the initial states. The Hugoniot relation is essentially a balance between the $E-E_{o h}$ and $P \Delta V$ terms in Eq. 9 and
\end{abstract}


this is realized only when the steam condenses completely into liquid, where $P$ can vary sensitively with $\rho$. Because the difference between the saturated volumes of liquid and vapor can become enormously large at low temperature, the initial condition $\mathrm{V}_{\text {oh }} \ll \mathrm{v}_{\mathrm{g}}$ required to observe the situation described in (1) can be met in a large portion of the coexistence region. However, if the initial state is located near the gaseous end of the coexistence region, the energy release during the condensation process dominates over the $P \Delta V$ work process. In this case, the pressure increases with the density inside and immediately outside the steam dome and the Hugoniot trajectory never completely extends to the liquid phase.
Extrapolation to higher temperatures of all Hugoniots in Fig。 9 leads to an ultimate compression of about eight times the initial state. Under the ideal-gas assumption, which is reasonable in this case, the Grüneisen $\gamma$ at such a compression is equal to $2 /\left[\left(\rho / \rho_{0}\right)-1\right]$, or about $2 / 7$ 。 This value lies close to the value of $\gamma=1 / 3$ when only the translational and rotational degrees in $\mathrm{H}_{2} \mathrm{O}$ molecules are fully excited. The lowest vibrational frequency of a water molecule is known to be $1954 \mathrm{~cm}^{-1}$ or $0.2 \mathrm{eV}^{25}$ This is consistent with our result that the internal molecular vibrations are only slightly excited at $0.1 \mathrm{eV}$.

Figure 12 shows the $\mathrm{P}-\mathrm{T}$ phase diagram of water and the four

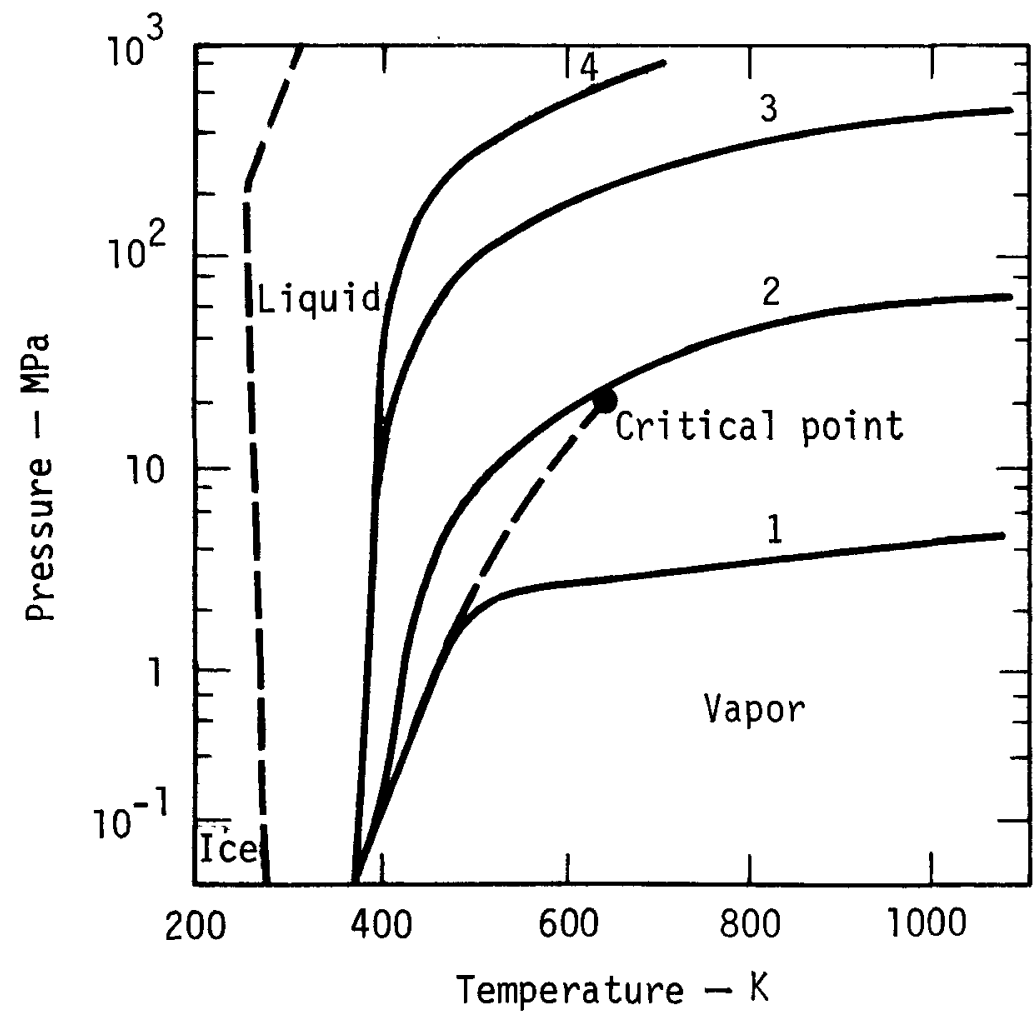

Fig. 12. Hugoniot trajectories of $\mathrm{P}$ vs $\mathrm{T}$ starting at a point $(101.3 \mathrm{kPa}$ and $373.15 \mathrm{~K}$ ) lying on the phase boundary. The initial volumes are $\mathrm{V}_{\mathrm{Oh}}=$ $1000,100,10$, and 3.33 $\mathrm{m}^{3} / \mathrm{Mg}$ for Hugoniots 1,2 , 3 , and 4 , respectively. 
Hugoniot trajectories originating from a common $(\mathrm{P}, \mathrm{T})$ point on the liquid-vapor phase line at $\mathrm{T}=373.15$ $K(P=103.3 \mathrm{kPa})$. The initial volumes of the Hugoniots are $\mathrm{V}_{\text {oh }}=$ $1000,100,10$, and $3.333 \mathrm{~m}^{3} / \mathrm{Mg}$. This figure clearly demonstrates that a wide range of thermodynamic states can be achieved by performing Hugoniot experiments that start from the phase line.

Figure $9 c$ shows that $U_{s}$ of the high-temperature Hugoniots ( 1 and 2) initially decreases with increasing $\mathrm{U}_{\mathrm{p}}$. It is difficult, at present, to understand the exact cause of the peculiar behavior. However, it is possible that the numerical procedure employed in the calculation might be the cause of this anomalous behavior.

BEHAVIOR OF THE TIGER DATA

As mentioned earlier, we did not use the TIGER-generated EOS data below $0.1 \mathrm{eV}$ at low density because experimental data were available in this region. Within this region, the dissociation of $\mathrm{H}_{2} \mathrm{O}$ molecules is not important and the thermodynamic behavior is essentially determined by the behavior of $\mathrm{H}_{2} \mathrm{O}$ molecules. To locate the range of applicability of the TIGER data, we made the TIGER calculation and compared the computational results with the experimental data. This is shown in Fig. 13 for pressure and energy along seven different isotherms. We note that the TIGER-generated data deviate from the experimental data when the density exceeds approximately $0.01 \mathrm{Mg} / \mathrm{m}^{3}$. This implies that the TIGER data become unreliable as soon as the nonideal effect begins to contribute to the EOS data. There is a simple explanation for this. The BKW equation for pressure used in the TIGER code contains the contribution from the repulsive intermolecular forces but neglects the contribution from the attractive intermolecular forces. The repulsive interactions typically are stronger and of shorter range than are the attractive forces. Thus, at the relatively low temperature and density considered here, the attractive contribution actually dominates the repulsive forces if the density lies below $0.01 \mathrm{Mg} / \mathrm{m}^{3}$. However, at temperatures above $0.1 \mathrm{eV}$ where the TIGER data are actually used, the influence of the attractive interactions is progressively diminished. Therefore, the range of applicability of the TIGER data can be extended to higher densities.

Figure 13a shows that the TIGERgenerated data produce a grossly distorted steam dome at high temperature, overestimating the critical pressure by about 100 times and the critical temperature by about 2 times. 


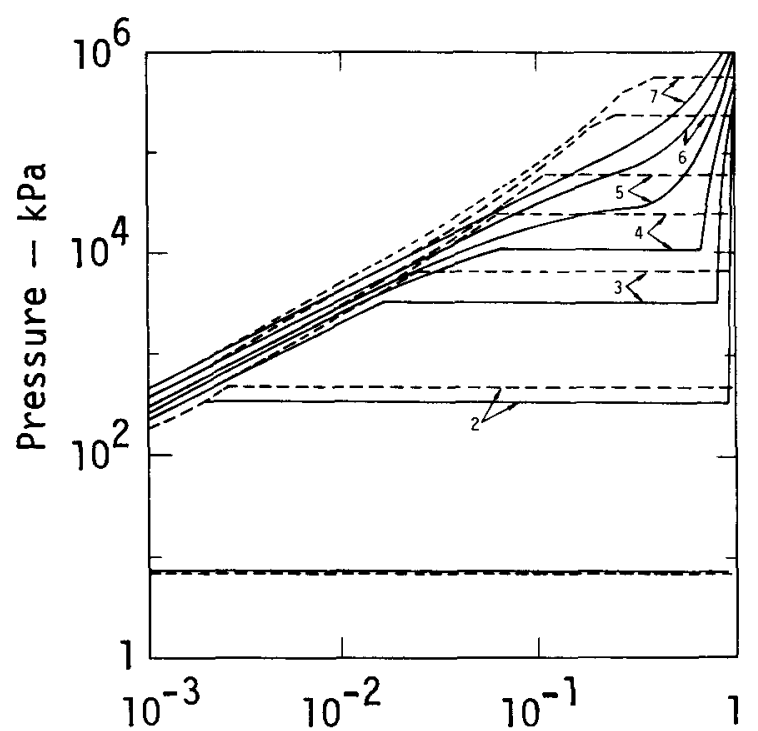

(a)

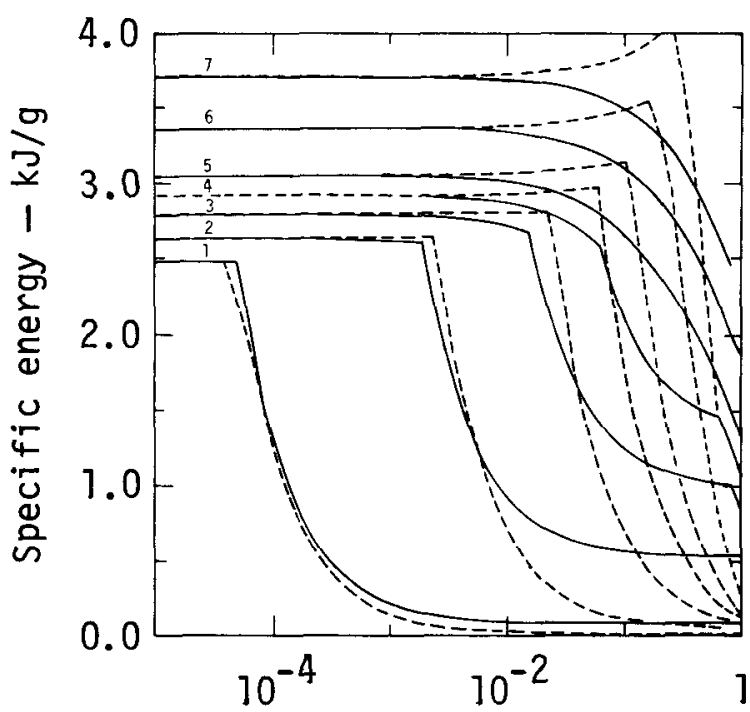

(b)

Density $-\mathrm{Mg} / \mathrm{m}^{3}$

Fig. 13. Comparison of TIGER (broken line) and EXPERIMENTAL (solid lines) data below $0.1 \mathrm{eV}$ : (a) $P$ vs $\rho$ isotherms and (b) $E$ vs $\rho$ isotherms. Note that the EOS table constructed for this report does not use the TIGER data shown here. Isotherms 1 through 7 begin at the following respective initial temperatures: $313.15,413.15,513.15,593.15,673.15,853.15$, and $1033.15 \mathrm{~K}$.

This deviation again results from the repulsive interaction in the $\mathrm{BKW}$ equation. Thermodynamically, the repulsion in the BKW equation increases the free energy of the gaseous phase with respect to that of liquid water. The theoretical system adjusts by forming more condensed species than that actually present. Consequently, the liquid phase remains stable beyond the observed critical point and the two-phase region in the TIGER calculation is extended to higher temperature. On the other hand, the attractive interactions tend to lower the free energy, therefore reducing the repulsive contribution to the free energy. Thus, to describe the low-temperature behavior of water, the $\mathrm{BKW}$ equation in the TIGER code should be modified to take proper account of the attractive contribution.

The higher-order thermodynamic quantities predicted from the TIGER calculation also warrant study. Figure 14 shows the specific heat at constant volume $\left(\mathrm{C}_{\mathrm{v}}\right)$ vs $\rho$ at fixed values of $\mathrm{T}$ to $0.1 \mathrm{eV}$. Below $\mathrm{T}=$ $0.07 \mathrm{eV}$, the $\mathrm{C}_{\mathrm{v}}$ isotherms exhibit a 


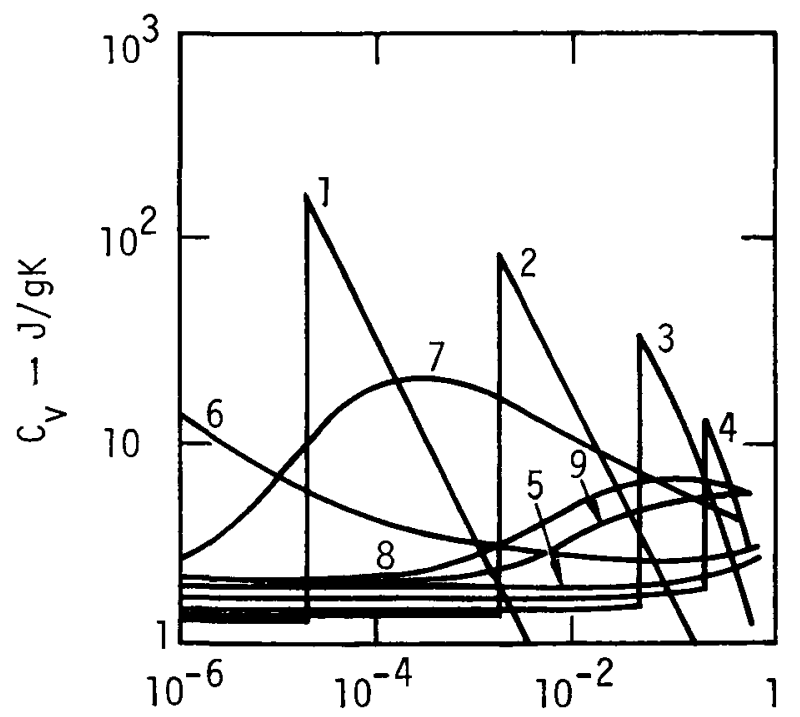

(a) Density $-\mathrm{Mg} / \mathrm{m}^{3}$

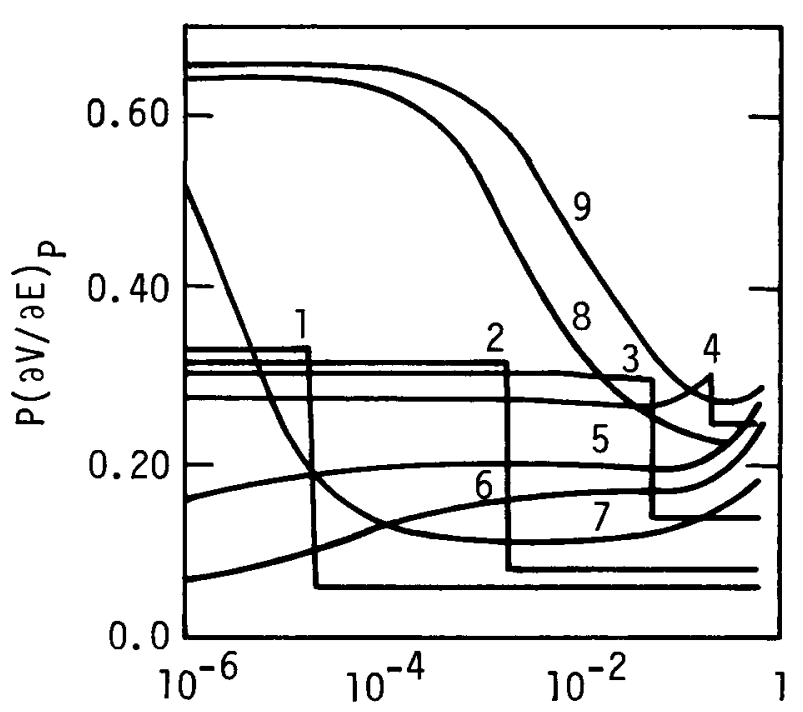

(b) Density $-\mathrm{Mg} / \mathrm{m}^{3}$

Fig. 14. Isotherms of higher-order thermodynamic quantities of water as calculated from the TIGER code: (a) constant volume specific heat vs $\rho$ and (b) $P(d V / d E)$ vs $\rho$. Isotherms 1 through 9 begin at the following respective initial temperatures: $0.025,0.035,0.05,0.07,0.15,0.2,0.4,0.8$, and $1.0 \mathrm{eV}$.

discontinuity at the two-phase boundary. At higher $\mathrm{T}$, the $\mathrm{C}_{\mathrm{v}}$ isotherms reach a maximum in density. This behavior occurs because water in this range dissociates into lower molecular weight species.

The quantity $\eta$ shown in Fig. 14b is defined as

$$
\eta=P(\partial V / \partial E)_{P},
$$

and measures the $P \Delta V$ work necessary to increase the energy of the system by a unit amount along an isobar. This quantity can be measured by isobaric experiments. ${ }^{26}$ Quantity $n$ becomes exactly equal to the usual
Grüneisen $\gamma\left[\equiv V(\partial P / \partial E)_{V}\right]$ in the lowdensity limit. Both quantities closely follow each other over the $\rho-T$ region studied in Fig. $14 \mathrm{~b}$. Within the two-phase region, $\eta$ can be shown to be exactly related to the temperature derivative of the vapor pressure. That is,

$$
n^{-1}=\frac{d \ln P}{d \ln T}-1
$$

Hence, $\eta$ is strictly independent of $\rho$ as can be seen in the isotherms (1-4) in Fig. 14b. This independence is not generally true for the Grüneisen $\gamma$. At fixed $\rho, \eta$ decreases at 
low $\mathrm{T}$ but increases at higher $\mathrm{T}$.

This is an expected behavior of a reacting gas as it undergoes a phase change. An extensive variation of $\eta$ (and $\gamma$ ) over $T$ and $\rho$ in Fig. 14 shows that a simple $\rho$-dependent (but T-independent) approximation of $\gamma$ used in a phenomenological EOS theory will become poor indeed. Likewise, Fig 14a shows that an often-used approximation of a constancy of $\mathrm{C}_{\mathrm{V}}$ no longer applies in this range.

\section{MIXTURE OF $\mathrm{SiO}_{2}$ AND $\mathrm{H}_{2} \mathrm{O}$}

To gain a qualitative insight into the thermodynamic behavior of a mixture containing $\mathrm{H}_{2} \mathrm{O}$, we chose a binary system containing $90 \mathrm{wt} \% \mathrm{SiO}_{2}$ and

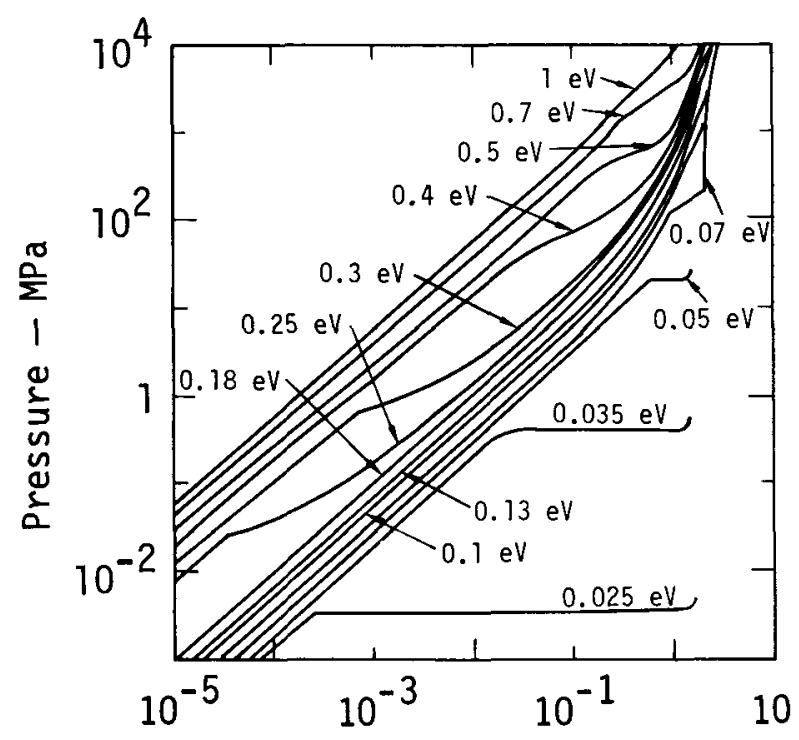

(a) Density $-\mathrm{Mg} / \mathrm{m}^{3}$
$10 \mathrm{wt} \% \mathrm{H}_{2} \mathrm{O}$. This weight percentage is representative of some naturally occuring hydrous minerals. The TIGER code was used to calculate the EOS data. The pressure isotherms to $1.0 \mathrm{eV}$ are shown in Fig. 15a. Figure $15 \mathrm{~b}$ presents an expanded view of the high- $\rho$, high-T portion of Fig. 15a. For $\mathrm{T} \geq 0.07 \mathrm{eV}$, the calculation includes the following species: gaseous $\mathrm{Si}, \mathrm{Si}_{2}, \mathrm{Si}_{3}, \mathrm{O}, \mathrm{O}_{2}, \mathrm{H}, \mathrm{H}_{2}$, SiO, $\mathrm{SiO}_{2}, \mathrm{OH}, \mathrm{SiOH}, \mathrm{Si}(\mathrm{OH})_{2}, \mathrm{SiH}$, and $\mathrm{SiH}_{4}$, liquid $\mathrm{Si}, \mathrm{SiO}_{2}$, and $\mathrm{H}_{2} \mathrm{O}$, plus solid $\mathrm{Si}$, and $\mathrm{SiO}_{2} \cdot$ In addition to those chemical species considered earlier in this work and in Ref. 8, gaseous $\mathrm{SiOH}, \mathrm{Si}(\mathrm{OH})_{2}, \mathrm{SiH}$ and $\mathrm{SiH}_{4}$ are also included in this work

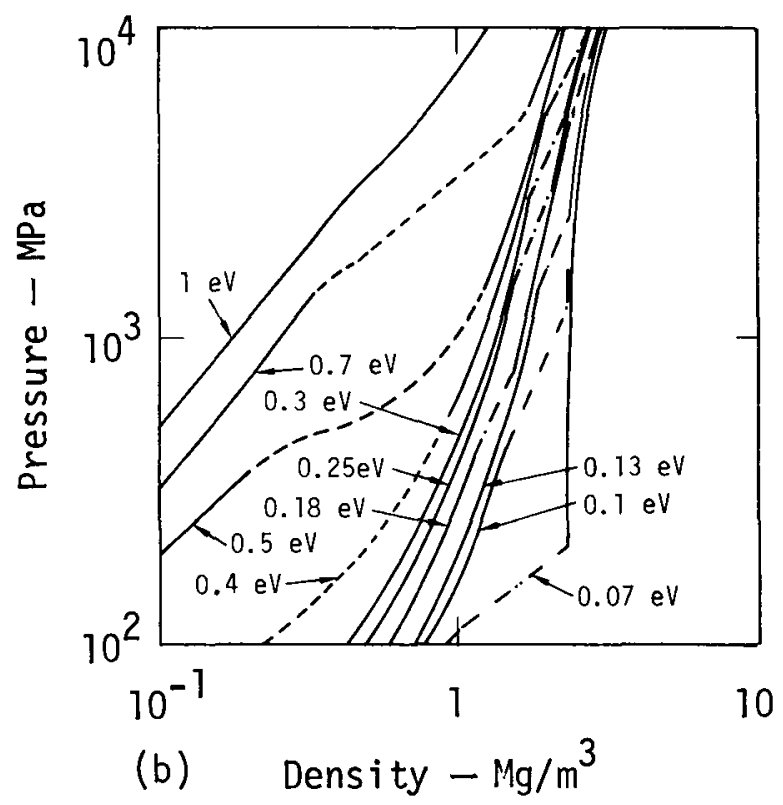

Fig. 15. The pressure isotherms of a mixed system composed of $90 \mathrm{wt} \% \mathrm{SiO}_{2}$ and $10 \mathrm{wt} \% \mathrm{H}_{2} \mathrm{O}$. The high-temperature and high-density portion of the isotherms indicated by thick lines in (a) is expanded in (b). Various possible phase changes are shown by broken lines: gaseous $\mathrm{SiO}_{2}-1$ iquid $\mathrm{SiO}_{2}$ -.--, 1iquid $\mathrm{SiO}_{2}$-solid $\mathrm{SiO}_{2}-\cdots-$, and gaseous $\mathrm{H}_{2} \mathrm{O}$-liquid $\mathrm{H}_{2} \mathrm{O}-\cdots-$. 
because the possibility of exchange reactions between $\mathrm{SiO}_{2}$ and $\mathrm{H}_{2} \mathrm{O}$ molecules cannot yet be ruled out. These potential reactions, however, do not contribute appreciably to the EOS data shown in Fig. 15. The isotherms in Fig. 15 kelow $\mathrm{T}=0.07 \mathrm{eV}$ are those of the TIGER data of pure water. However, the density of water is shifted to account for the fact that the mixture system contains only $10 \mathrm{wt} \% \mathrm{H}_{2} \mathrm{O}$. This is a reasonable procedure because only solid $\mathrm{SiO}_{2}$ exists below $\mathrm{T}<0.07 \mathrm{eV}$ and its contribution to the pressure at low density $\left(\leqslant 2.2 \mathrm{Mg} / \mathrm{m}^{3}\right)$ is neglible. This approximation was verified at $\mathrm{T}=0.07 \mathrm{eV}$; a very accurate $0.07 \mathrm{eV}$ isotherm was reproduced.

The isotherms in Fig. 15 display

a complex behavior. This results from the large difference in the boiling points of $\mathrm{SiO}_{2}$ and $\mathrm{H}_{2} \mathrm{O}$. The isotherms can be classified into four distinct regions plus three connecting transition regions. These are (1) gaseous $\mathrm{SiO}_{2}+$ gaseous $\mathrm{H}_{2} \mathrm{O}$, (2) liquid $\mathrm{SiO}_{2}+$ gaseous $\mathrm{H}_{2} \mathrm{O}$, (3) solid $\mathrm{SiO}_{2}+$ gaseous $\mathrm{H}_{2} \mathrm{O}$, and (4) solid $\mathrm{H}_{2} \mathrm{O}+$ liquid $\mathrm{H}_{2} \mathrm{O}$. Region (1) corresponds to the high-T, low-p portion in Fig. 15 while region (4) corresponds to the low-T, high-p portion. Within regions (1), (2), and (3) as well as within the transition regions, temperature is so high that water can exist only as vapor. Because $\mathrm{SiO}_{2}$ has been precipitated out in regions (2) and (3), the pressure of the system is essentially that of water vapor. The flat tieline observed in isotherms of the pure- $\mathrm{SiO}_{2}$ system $^{8}$ at the liquid-vapor and the liquidsolid transition regions does not appear in regions (2) and (3). Instead, the tieline is replaced by an isotherm with a small positive slope. The present system is basically a two-component system composed of $\mathrm{SiO}_{2}$ and $\mathrm{H}_{2} \mathrm{O}$. For such a system, the Gibbs-phase rule states that the two independent thermodynamic variables, $P$ and $T$, are required to specify the phase change. The same argument also holds true for the transition region of water that connects regions (3) and (4). In this case, however, the contribution of solid $\mathrm{SiO}_{2}$ to the pressure is so low (except at the high- $\rho$ end of the transition region) that the system acts as if it is undergoing a first-order phase change.

It is interesting that, in Fig. $15 \mathrm{~b}$, the liquid phase of water remains stable to at least $0.18 \mathrm{eV}$, considerably higher than the critical temperature ( $\simeq 0.1 \mathrm{eV}$ ) of pure water as predicted from the TIGER data. Apparently, the presence of condensed $\mathrm{SiO}_{2}$ alters the boiling temperature under pressure. A more detailed analysis of this mixed system would 
require the construction of a phase diagram of a binary mixture of $\mathrm{SiO}_{2}$ and $\mathrm{H}_{2} \mathrm{O}$ with variable concentrations at high pressure. Because the TIGER code was used, the numerical values quoted above are overestimated. However, at present there is no reason to doubt the theoretical prediction that the liquid region of water will be greatly enhanced in the binary system.

\section{Conclusion}

The EOS table in this work was constructed from a combination of several theoretical models and experimental data and is applicable over a large region of density and temperature. We believe that the table represents a reasonable EOS behavior within this range.

There are two areas of improvement that should be considered further. The first area concerns the chemical-reaction region as calculated by the TIGER code. A substantial improvement could be made here by adopting a better theoretical model for gaseous mixtures. The model should include the contribution from the attractive intermolecular forces. This would allow the extension of the calculation to low temperature. The second area of improvement relates to the hole region that connects the experimental data and the MASTER data (see Fig. 1). The missing data could be filled in with a theoretical code such as GRAY. 27,28 The parameters in GRAY must be optimized to agree with the experimental data. For water, this is not a trivial task because $\mathrm{H}_{2} \mathrm{O}$ has several internal degrees of freedom. An alternative approach would be to employ perturbation theories of fluids that have been developed recently. 29 These theories have been successfully applied to simple systems and can be extended to apply to water. Because water is one of the simpler polyatomic systems and because the intermolecular potential of water has been investigated extensively, 30,31 such a firstprinciple approach will yield a clear understanding of high-pressure behavior of water.

\section{Acknowledgments}

I thank R. Grover, H. Graboske, $\mathrm{J}$. Shaner, and D. Young for informative discussions during the course of this work. J. Walton and E. Lee generated the input parameters necessary for the TIGER code. Technical assistance was provided by E. Collins, S. Link, and B. Hodge. 


\section{References}

1. D. Eisenberg and W. Kauzmann, The Structure and Properties of Water, (Oxford Clarendon Press, 1969).

2. E. Schmidt, Properties of Water and Steam in SI-Units, (Springer-Verlag New York Inc., 1969).

3. C. W. Burnham, J. R. Holloway, and N. F. Davis, Thermodynamic Properties of $\mathrm{H}_{2} \mathrm{O}$ to $1000^{\circ} \mathrm{C}$ and $1 \mathrm{kbar}$, (The Geological Society of America Special Paper No. 132, 1969).

4. M. H. Rice and J. M. Walsh, "Equation of State of Water to 250 Kilobars," J. Chem. Phys., 26, 824 (1957).

5. A. A. Bakanova, V. N. Zubarev, Yu. N. Sutulov, and R. F. Trunin, "Thermodynamic Properties of Water at High Pressures and Temperatures," Sov. Phys. JETP 41, 544 (1976).

6. G. A. Gurtman, J. W. Kirsch, and C. R. Hastings, "Analytical Equation of State for Water Compressed to 300 Kbar," J. App Z. Phys., 42, 851 (1971).

7. F. H. Ree, Equation-of-State of Plastics: Polystyrene and Its Foams, Lawrence Livermore Laboratory, Rept. UCRL-51885 (1975).

8. F. H. Ree, Equation-of-State of the Silcon Dioxide System, Lawrence Livermore Laboratory, Rept. UCRL-52153 (1976).

9. M. Cowperthwaite and W. H. Zwisler, TIGER Program Documentation, Stanford Research Institute, Publication No. Z106, Vol. I (1973), Vols. II-IV (1974).

10. R. D. Cowan and W. Fickett, "Calculation of the Detonation Properties of Solid Explosives with the Kistiakowsky-Wilson Equation-of-State," J. Chem. Phys., 24, 932 (1956).

11. J. Walton and E. Lee, Lawrence Livermore Laboratory, private communication (1976).

12. D. R. Stull and H. Prophets, Eds., JANAF Thermochemical Data, NSRD-NBS 37 (1971), 2nd Ed. (U.S. Government Printing Office, Washington, D.C.), Catalog No. C13.48:37.

13. C. A. Rouse, "Ionization Equilibrium Equation-of-State. V. Twenty-Two Element Mixtures at Stellar Temperatures and Densities," Astrophys. J., 137, 1286 (1963) and references cited therein.

14. J. L. M. Cortez and C. S. Lacey, Lawrence Livermore Laboratory, Internal Document UCON 75-11 (1975). Readers outside the Laboratory who desire further information on LLL internal documents should address their inquiries to the Technical Information Department, Lawrence Livermore Laboratory, Livermore, California, 94550.

PLL/gw/vt/gw 
15. K. Johnson, Lawrence Livermore Laboratory, Internal Document HTN-252 (1976).

16. S. L. McCarthy, The Kirahnits Corrections to the Thomas-Fermi Equationof-State, Lawrence Livermore Laboratory, Rept. UCRL-14363 (1965).

17. D. T. Warren, Nuclear Correction for Genesis, Lawrence Livermore Laboratory, Rept. UCID-15316 (1968).

18. K. Johnson, Lawrence Livermore Laboratory, Internal Document HTN-260 (1976).

19. J. M. Walsh and M. H. Rice, "Dynamic Compression of Liquids from Measurements on Strong Shock Waves," J. Chem. Phys., 26, 815 (1957).

20. M. Van Thiel, A. S. Kusubov, and A. C. Mitche11, Compendium of Shock Wave Data, Lawrence Livermore Laboratory, Rept. UCRL-50108 (1965).

21. C. W. Burnham, J. R. Holloway, and N. F. Davis, "The Specific Volume of Water in the Range 1000 to 8900 bar, $20^{\circ}$ to $900^{\circ} \mathrm{C}, " \mathrm{Am}$. J. Sci. Schairer 267-A, 70 (1969).

22. Those readers wishing to see the entire EOS table should contact the author.

23. W. Ne1lis and J. Shaner, Lawrence Livermore Laboratory, private communication (1976).

24. W. H. Gust and J. W. Shaner, Lawrence Livermore Laboratory, private communication (1976).

25. A. S. Friedman and L. Haar, "High-Speed Computation of Idea1 Gas Thermodynamic Functions. Isotopic Water Molecules," J. Chem. Phys., 22, 2051 (1954).

26. G. R. Gathers, J. W. Shaner, and D. A. Young, "Experimental, Very HighTemperature, Liquid-Uranium Equation of State," Phys. Rev. Lett., 33, TC (1974).

27. E. B. Royce, GRAY, Three-Phase Equation of State for Metals, Lawrence Livermore Laboratory, Rept. UCRL-51121 (1971).

28. R. Grover, "Liquid Metal Equation of State on Scaling," J. Chem. Phys., 55, 3434 (1971).

29. H. C. Anderson, "The Structure of Liquids," Ann. Rev. Phys. Chem., 26, 145 (1975).

30. 0. Matsuoka, E. Clementi, and M. Yoshimine, "CI Study of the Water Dimer Potential Surface," J. Chem. Phys., 64, 1351 (1976).

31. A. Rahman, F. H. Stillinger, and H. L. Lemberg, "Study of A Central Force Model for Liquid Water by Molecular Dynamics," J. Chem. Phys., 63, 5223 (1975). 